\title{
Insight into Concept and Progress on Pharmaceutical Co-Crystals: An Overview
}

\author{
Venkata Deepthi Vemuri ${ }^{1, *}$, Srinivas Lankalapalli ${ }^{2}$ \\ ${ }^{1}$ Maharajah's College of Pharmacy, Phool Baugh, Vizianagaram, Andhra Pradesh, INDIA. \\ ${ }^{2}$ GITAM Institute of Pharmacy, GITAM (Deemed to be University), Visakhapatnam, Andhra Pradesh, INDIA.
}

\begin{abstract}
Pharmaceutical co-crystals have conferred significant recognition in recent past as a new solid form by virtue their capability to modulate physicochemical properties of Active Pharmaceutical Ingredient (API). Nevertheless, pharmaceutical progress of cocrystals could be provocation, the requirement for high-throughput screening methods and the techniques capable of co-crystal production in industrial scale still hamper the co-crystal used by industries. In this review, well ordered overview of pharmaceutical co-crystal is provided, with focus on role of supramolecular chemistry, co-crystal design strategies, preparation methods, physicochemical property studies, mechanism of solubility enhancement, evaluation techniques. In the present commentary, the impact of choosing appropriate process design and formulation on translational challenges has been discussed. Eventually, a short outline of applications and marketed drug products of pharmaceutical co-crystal drug substance is also described.
\end{abstract}

Key words: Co-crystals, Crystal engineering, Physicochemical properties, Co-crystallization, Translational challenges.

\section{INTRODUCTION}

The process of developing a new dosage form from a new chemical entity is a complex process. It involves in strategic and exploratory research in the selection and development of medical product. Whereas the molecule has to pass different stages of development to reach the required criteria. Incomplete information about its properties and pharmaceutical manufacturing capabilities in advance to clinical trials may lead to complex and costly problems at the later stage. ${ }^{1}$ Considering these cases improving the existing molecules founds more beneficial than the new molecule. Most of the solid-state Active Pharmaceutical Ingredients (APIs) exist mainly in two morphological structures crystalline or amorphous (Figure 1). Among these crystalline materials are more preferred for product development due to their high stability when compare to the amorphous forms (less stable and leads to re-crystallization over time)..$^{2}$ Even though crystal forms are stable, reproducible and easily purifiable than other types of solids the major drawback is its low solubility. Amid all the biopharmaceutical properties, solubility remains as main issue for most of the API's. ${ }^{3}$ Solubility and dissolution rates are the most important considerations to determine the performance of the drug. Improvement in these aspects without change in the molecular structure is the most challenging aspect for successful development of new product. Currently, many strategies have been adopted for improving the solubility to attain the improvement in their absorption and bioavailability of the drugs, including milling techniques, ${ }^{4}$ hot melt extrusion, ${ }^{5}$ self-emulsification, ${ }^{6}$ soliddispersion, ${ }^{7}$ inclusion-complex ${ }^{8}$ liposomal formulations, ${ }^{9}$ nanoparticles. ${ }^{10}$

Co-crystallization is one of the alternative ways to solve the problems confined with the physicochemical properties of the
Submission Date: 17-07-2019; Revision Date: 26-09-2019; Accepted Date: 12-10-2019

DOI: 10.5530/ijper.53.4s.147 Correspondence: Mrs. Venkata Deepthi Vemuri,

Assistant Professor, Maharajah's College of Pharmacy, Phool Baugh, Vizianagaram-535002, Andhra Pradesh, INDIA.

Phone: +919032292387

E-mail: deepthichowdary438@ gmail.com

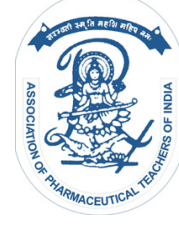

www.ijper.org 
API. Over the last twenty years a number of publications have been shown the significant increase in the use of co-crystal and their possible use in the formulation as an optimization strategy for solubility, dissolution rate, physical stability and bioavailability of API's. ${ }^{11}$ This is encouraged by the recent FDA reclassification, from which co-crystals are considered as drug polymorph rather a new API, ${ }^{12,13}$ including solvates to ease the regulation burden on manufacturers that work with them. ${ }^{12,13}$ Many of co-crystal strategies like solvent change techniques, ${ }^{14}$ Solution co-crystallization, ${ }^{15}$ thermal methods, ${ }^{16}$ ultrasound assisted, ${ }^{17}$ grinding methods ${ }^{18}$ have been emerged. Previously, many of the case studies and reviews conducted in co-crystals reported, superiority of co-crystallization technology in comparison to other strategies, ${ }^{19}$ improvements in manufacturing of drug dosage forms,${ }^{20}$ enhancements in drug properties by bottom-up approach, ${ }^{21}$ pharmaceutical co-crystallization techniques, ${ }^{22}$ translational development challenges, ${ }^{23}$ impact of co-crystals on drug pharmacokinetics, ${ }^{24}$ Co-crystallization of neutraceuticals, ${ }^{25}$ Vibrational spectroscopic investigations on co-crystallization. ${ }^{26}$ Improvement of physicochemical properties of co- crystallization have been well explored. ${ }^{27}$

\section{Supra-molecular chemistry and crystal engineering}

The scientific community had some disagreement with co-crystal definitions which were subjected in the past. European medicine agency defined co-crystal as a crystalline homogeneous structure having two or more components arranged in a crystal lattice with a definite stoichiometric ratio (EMA 2015). Co-crystals are formed by intermolecular interactions such as halogen bonding electrostatic interactions, $\pi$ stacking, hydrogen bonding and Vander walls forces which are non-covalent between API and the co-former. ${ }^{20,28}$ Figure 2 shows the schematic formation of co-crystal. Supramolecular synthons, homo-synthons and hetero-synthons ${ }^{29}$ refer to structural units within supramolecules which are formed by intermolecular interaction by known synthetic operations. ${ }^{30} \mathrm{~A}$ comparison between FDA and EMA guidelines of Pharmaceutical co-crystals was discussed in Table $1 .^{31}$

Crystal engineering involves breaking and forming noncovalent bonds, rearrangement of molecules within the crystal packing. In turn, it is effective in designing supramolecular synthons ${ }^{32,33}$ and ultimately results in co-crystals formation, which may lead to the improvement of physicochemical properties of API without affecting its structure and functions. An acid group of carboxylic acids, alcohol groups and amide groups are the com-

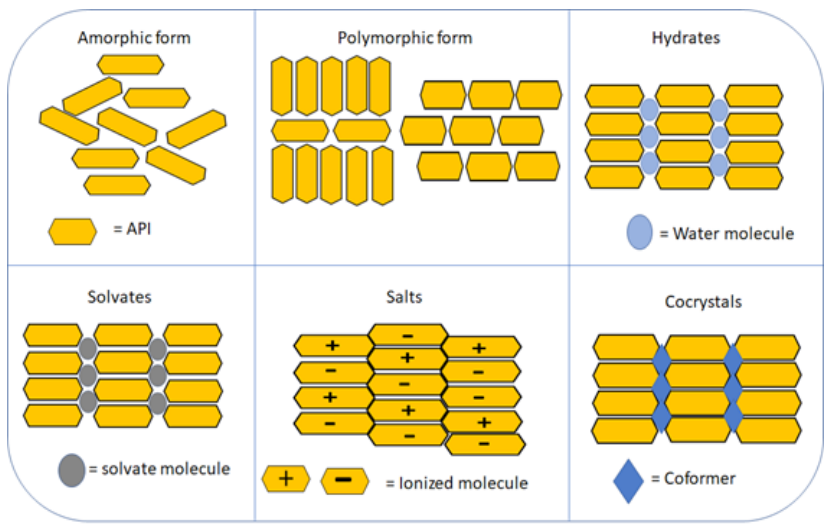

Figure 1: Schematic representation of solid forms classification.

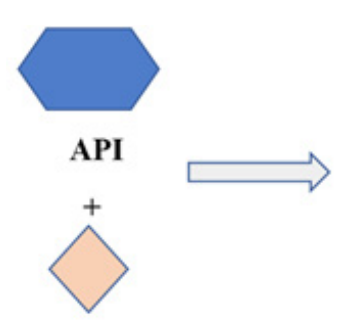

Coformer

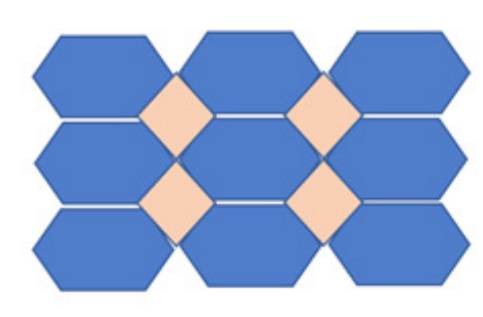

Cocrystal
Figure 2: Schematic representation of co-crystal formation.

\begin{tabular}{|c|c|c|}
\hline $\begin{array}{c}\text { Table 1: Comparison between FDA and EMA guide- } \\
\text { lines of Pharmaceutical co-crystals. }{ }^{31}\end{array}$ & FDA (2016) \\
$\begin{array}{c}\text { Regulatory } \\
\text { guidelines }\end{array}$ & \multicolumn{2}{|c|}{ EMA (2015) } \\
\hline $\begin{array}{c}\text { Regulatory } \\
\text { category }\end{array}$ & $\begin{array}{c}\text { Active } \\
\text { pharmaceutical } \\
\text { ingredient }\end{array}$ & $\begin{array}{c}\text { Polymorph of active } \\
\text { pharmaceutical } \\
\text { ingredient }\end{array}$ \\
\hline Composition & $\begin{array}{c}\text { Active } \\
\text { pharmaceutical } \\
\text { ingredient and } \\
\text { co-former in fixed } \\
\text { stoichiometric } \\
\text { arrangement }\end{array}$ & $\begin{array}{c}\text { Active } \\
\text { pharmaceutical } \\
\text { ingredient and a } \\
\text { food or drug grade } \\
\text { co-former }\end{array}$ \\
\hline Co-former role & Reagent & Excipient \\
\hline Interaction in crystal & $\begin{array}{c}\text { Non - ionic / non- } \\
\text { covalent interaction }\end{array}$ & $\begin{array}{c}\text { Non - ionic / non- } \\
\text { covalent interaction }\end{array}$ \\
\hline $\begin{array}{c}\text { New active } \\
\text { substance } \\
\text { registration }\end{array}$ & $\begin{array}{c}\text { Possible if shown } \\
\text { dissimilar in } \\
\text { efficacy/safety }\end{array}$ & No \\
\hline Classification & $\begin{array}{c}\text { Salt of Active } \\
\text { pharmaceutical } \\
\text { ingredient. }\end{array}$ & $\begin{array}{c}\text { Polymorph of Active } \\
\text { pharmaceutical } \\
\text { ingredient. }\end{array}$ \\
\hline
\end{tabular}

mon functional groups involving in supra-molecular synthon formation by H-bonding. ${ }^{34,35}$ Co-crystal formation is more favored by hetero-synthons than homosynthons, ${ }^{36,37}$ The intermolecular interactions involved in co-crystal formulations should be non-ionic, ${ }^{34}$ with no proton transfer. If the proton transfer is completed 
it leads to salt formation. ${ }^{38}$ This proton transfer mainly depends upon the pKa values of the API and coformers. According to $\mathrm{FDA}^{39} \Delta \mathrm{pKa}$ is considered as a threshold for distinguishing between co-crystals and salt. FDA also indicates, the formation of salt will happen in the components having $\Delta \mathrm{pKa} \geq 1$. If the component having $\Delta \mathrm{pKa}<1$ result in co-crystal formation. In addition to FDA indications, others expressed "rule of thumb" states $\Delta \mathrm{pKa}>2.7-3$ units, formation of salt is likely to happen than cocrystal. ${ }^{40}$

Fine-tuning of API properties by using crystal engineering would be beneficial to the pharmaceutical industry. Co-crystals found to be better than salts, polymorphism, solvates and amorphous forms

\section{Effect of co-crystals on physicochemical properties of API}

Along with all other aspect's investigations of physicochemical properties plays most important role in developing the new dosage form. ${ }^{41}$ These physicochemical properties of the drugs can be adjusted with an increased instability and efficiency of dosage form by using co-crystallization techniques. ${ }^{42}$ Schultheiss and Newman gave a review based on these properties and some of the key physicochemical properties are melting point, solubility, stability dissolution bioavailability. ${ }^{43}$

\section{Melting point}

Melting point, as it is having a correlation with aqueous solubility and vapour pressure ${ }^{44}$ used in purity identification and characterization. Melting point is one of the key factors essential to characterize the polymorphs of a compound (Monotropic or Enterotropic). ${ }^{45}$ Many of the researchers stated that the co-crystals provide an excellent opportunity in modifying and fine-tuning the physicochemical properties of the existing molecules. ${ }^{43,21,46}$

A comparison melting point study was done by Staton and Bak using 10 co-crystals with API AMG517 with their respective co-formers, among these all the co-crystals have shown the melting point between the melting points of API and their corresponding co-formers. ${ }^{21}$ Linear correlation between the melting points of hexamethylene bisacetamide co-crystals were reported with five different even numbered aliphatic dicarboxylic acid co-formers which are selected with similar structures and different melting points. ${ }^{46}$

Nate Schulthesis, 2009 conducted a survey on 50 cocrystal samples, the majority of them have shown the melting point between that of the API and co-formers. ${ }^{43}$ Fleischman, 2003 carried out to investigate on the on four co-crystals with different crystal packing arrange- ment but same heteromeric $\mathrm{O}-\mathrm{H} \ldots \mathrm{N}$ hydrogen bond. These co-crystals had different melting points showing the impact of crystal packing arrangement on melting point. ${ }^{47}$

\section{Stability}

Stability is the most important parameters to be studied during the development of any new molecule the selflife of the molecule mainly depend upon the chemical and physical stabilities (ICHQ1A). The following are the aspects to be considered for stability testing.

\section{Relative humidity (RH) stress}

$\mathrm{RH}$ stress provides the information about the water content in co-crystals which leads to deterioration of molecules. This in turn helps in determining the best storage condition. ${ }^{48}$

Many of the literature concluded that the co-crystals are stable to moisture under normal storage conditions. ${ }^{49-52}$ Dynamic vapour sorption and desorption experiments on co-crystals of Indomethacin saccharin (1:1) showed a very negligible amount of moisture was sorbed by co-crystals with no solid-state transformation. ${ }^{49} \mathrm{MC}$ Namara conducted repeated sorption/desorption cycles on co-crystals of glutaric acid and 2-(4-(4-choro-2-flurphenoxy) phenyl) pyrimidine -4-caroxamide. The data revealed that the moisture uptake is less the $0.008 \%$ and the relative humidity was up to $95 \% .{ }^{50} \mathrm{Bak}$ A showed that AMG517/sorbic acid co-crystals with minimum moisture update $0.7 \%$ and with no solid-state transformation with sorption/desorption cycle. ${ }^{27}$

Some of the literature supported with adequate physical stability of co-crystals even in the long-term stability studies concerning for to RH. ${ }^{52}$ Trask conducted studies with 6 caffeine co-crystals which were placed at 4 RH conditions $(0,43,75$ and $98 \% \mathrm{RH})$. These samples were analyzed after 1, 3, 7 days and 7 weeks. This study reveals using strong acid with caffeine produced the most stable co-crystal whereas weakest acid gave the least stable co-crystal..$^{53}$

\section{Thermal stress}

This is the most important parameter used to determine physical and chemical stability. ${ }^{54,55}$ Chen prepared cocrystals of a monophosphate salt and phosphoric acid with were exposed to $60^{\circ} \mathrm{C}$ for 8 -weeks and noticed with no degradation. ${ }^{56}$

\section{Chemical stability}

These studies were normally conducted using accelerated stability conditions such as $40^{\circ} \mathrm{C} / 75 \% \mathrm{RH}$ and $60^{\circ} \mathrm{C} / 75 \% \mathrm{RH}$ to minimize the chemical degradation of the formulation. Only limited research work was done 
on the chemical stability of co-crystals. Chen, 2007, conducted stability studies of co-crystals of monophosphate salt with phosphoric acid using $40^{\circ} \mathrm{C} / 75 \% \mathrm{RH}$ and $60^{\circ} \mathrm{C} / 75 \% \mathrm{RH}$ for 8 weeks and reported to have no detectable degradation. ${ }^{56}$ Another study was conducted with co-crystals of 2-(4-(4-chloro-2-fluorphenoxy) phenyl) pyrimidine-4-carbonxamide with glutaric acid using same conditions for 2 months and reported with no detectable degradants by HPLC impurity analysis. ${ }^{50}$ Another literature compared the chemical stability of carbamazepine (parent API) with 1:1 carbamazepine saccharin (co-crystals) using temperatures of $5^{\circ} \mathrm{C}$, $40^{\circ} \mathrm{C}$ and $60^{\circ} \mathrm{C}$ at ambient humidity and elevated $\mathrm{RH}$ conditions of $25^{\circ} \mathrm{C} / 60 \% \mathrm{RH}$ and $40^{\circ} \mathrm{C} / 75 \% \mathrm{RH}$ for 2 months. Results revealed with no degradation at different temperatures and similar degradation with second condition. ${ }^{57}$ Based on these literatures we notice that the co-crystals may exhibit better chemical stability.

\section{Solution Stability}

Solution stability is defined as the ability of co-crystals to stay in solution without converting into crystals. ${ }^{43}$ Solution stability along with solubility and dissolution studies play a very important role in understating the nature of co-crystals in releasing media. Trask 2006 along with $\mathrm{RH}$ studies, conducted a solution stability test for 2:1 caffeine/oxalic acid co-crystals by preparing slurry with water at ambient temperature for two days and noticed that there is no change in its physical form indicating the stability of co-crystals. In another example the study involved in the screening of twenty carbamazepine co-crystals formed with 18 co-formers which were slurred with water for 20-48 hr. Among these, only seven co-crystals maintained their structure and remains are converted to carbamazepine dihydrate. The Author noted that the high aqueous solubility of co-formers has the chances of structural instability. ${ }^{58}$ Solution stability can be obtained by solubility and intrinsic dissolution experiments in aqueous media. MC Namara, 2006 conducted an intrinsic dissolution experiment on co-crystals of 2-[4-(4-Chloro-2Flourphenoxy) Phenyl] Pyrimidine - 4 - Carboxamide with Glutaric acid for $90 \mathrm{~min}$ at $37^{\circ} \mathrm{C}$ using water. Results showed that there is no major conversion to parent molecule, the remaining portion left in the apparatus showed the complete conversion to the parent molecule within 24 hrs under $37^{\circ} \mathrm{C} .5^{50}$ Another literature conducted aqueous solubility on 4 co-crystals of Fluoxetine $\mathrm{Hcl}$ with Benzoic acid, Fumaric acid and Succinic acid. Among these co-crystals Benzoic and Fumaric acids showed no change in its structure at the end of the experiment. But
Succinic acid co-crystals exhibited complete conversion to Fluoxetine Hydrochloride. In this study, the author reported that the Succinic acid is a conformer having highest solubility and it was co-former to dissociate. ${ }^{59}$

\section{Solubility}

Solubility is the thermodynamic equilibrium of solute between the liquid phase and solid phase. ${ }^{60,61}$ Pharmaceutical co-crystallization is considered to be the most effective way of improving the solubility on which many of the researches have been reported. ${ }^{3,46,50,59}$ Ramenar compared three Itraconazol co-crystals with crystalline Itraconazol and reported with high solubility of co-crystals than crystalline form. ${ }^{62}$ Shiraki prepared 2 co-crystals, Exemestane/Maleic acid and megestrol acetate/saccharin from organic solutions with different particle sizes. Both the co-crystals showed improvement in dissolution rates at the initial stage when compared to the respective original crystals. Fine particle co-crystals of Megestrol acetate/saccharin showed supersaturated concentration of Megestrol acetate for about 6 folds more than MA within 15 min and 2 folds more within 4 hr. Co-crystals of Exemestane/Maleic acid transformed to parent crystal within $1 \mathrm{~min}$ in suspension. These cocrystals even larger particles have shown higher dissolution rates ${ }^{63}$ Good and Redriguez-Hornedo, 2010 published a theoretical analysis for predicting the cocrystals solubility. Co-crystal eutectic constant $\left(\mathrm{K}_{\mathrm{eu}}\right)$ Plays a major role in the selection synthesis and formulation of co-crystals. $\mathrm{K}_{\mathrm{eu}}$ values were used to predict the phase behavior, ionization and complexation. ${ }^{64}$ Co-crystallization approach for poorly soluble drugs like Carvedilol shown better bioavailability, solubility and dissolution in comparison to other strategies. ${ }^{19} \mathrm{~A}$ NMR crystallographic study on niclosamide co-crystals, reported the improvement of equilibrium solubility of 1:1 niclosamide - thiazole cocrystals 2.8 folds to that of pristine niclosamide. ${ }^{65}$

\section{Mechanism involved in solubility enhancement}

Solubility depends mainly on crystal lattice strength and solvent affinity. Co-crystals have the ability to reduce the lattice strength and to enhance the solvent affinity. ${ }^{66,67}$ Aqueous solubility of the co-crystals is mainly affected by solvation, leads to an increase in drug hydrophobicity. ${ }^{68,69}$ Due to this hydrophobicity, many of the co-crystals of hydrophobic drugs have shown less solubility than that determined using lattice energy. ${ }^{27,67}$ Many of the literatures correlated the solubility of co-formers with the solubility of co-crystals. ${ }^{67,70}$ This indicates that the nature of co-formers will affect the solvation barrier of co-crystals. 


\section{Spring and Parachute effect}

Spring and Parachute phenomenon was explained by Guzman, this concept improves the solubility of hydrophobic drugs by using a supersaturation strategy. This mechanism involves in the origination of supersaturated Metastable state and its maintenance. ${ }^{71}$ The weak Bonds (Hydrogen bonds) that connects the drug and the co-former in co-crystals ${ }^{72}$ are dissociated, which leads to the release of high water-soluble co-former from the crystal lattice of co-crystal to the biological medium. The Hydrophobic drug has been converted to supersaturation state which is having higher energy than its crystalline molecule called spring. This spring will precipitates to clusters immediately. The maintenance of this super saturated stage for a sufficient period is beneficial for improving the solubility Figure 3. Using some of the excipients or compounds which intervene with crystal growth may lead to inhibit the precipitate and maintain spring state this referred to as parachute. This state lasts for a long time in the dissolution medium showing high solubility. This stage transformer follows Ostwald's Law of stages. ${ }^{63-74}$ Childs, 2013 prepared 1:1 Danazol/Vanillin co-crystals which results in 1.7 times rise in AUC with simple aqueous suspension. Whereas these co-crystals have shown 10 times rise in AUC when suspended in the aqueous phase containing TPGS and HCP as solubilizes and precipitate inhibitor respectively. ${ }^{75}$

\section{Intrinsic dissolution}

Intrinsic dissolution indicates the rate of dissolution of a compound from constant particle size. Intrinsic dissolution rate is one of the best indicators for the in vivo performance of most of the co-crystals, which belongs to BCS class II drugs. Only limited numbers of literatures are available on intrinsic dissolution..$^{50,59,63} \mathrm{M} \mathrm{C}$ Namara conducted intrinsic dissolution studies on glutaric acid co-crystals of 2-[4-(4-Chloro-2Flourphenoxy) Phenyl] Pyrimidine - 4 - Carboxamide using water over $90 \mathrm{~min}$. This study was reported to increase in dissolution of co-crystals with 18 times than that of the parent molecule..$^{50}$ Another study was conducted on three co-crystals of Fluoxetine $\mathrm{HCl}$ and different co-formers, 2:1 Fluoxetine $\mathrm{HCl} /$ Succinic acid co-crystals have shown a threefold increase of dissolution over parent molecule, 2 co-crystals which are made up of Benzoic acid and Fumaric acid showed reduced and same dissolution rates respectively with the comparative parent molecule. ${ }^{59}$ Shiraki measured intrinsic dissolution on 2 co-crystals. 1:1 Exemestane/Maleic acid showed the same dissolution rate as parent molecule whereas 1:1 Megestrol acetate/saccharin co-crystals showed a 3-4- fold increase in dissolution rate than the parent molecule. ${ }^{63}$ More studies should be needed for the exact role of co-crystallisation on the intrinsic dissolution rate.

The melting point of most co-crystals is resulting in the melting points between API and co-former. In most cases, stability was improved resisting hydrate formation was shown in co-crystals. Solubility and dissolution improvement for poorly soluble compounds were achieved by co-crystallization. It was shown that a worthy degree in bioavailability is possible with co-crystals.

\section{Formulation of co-crystals}

\section{Design strategy and co-former selection}

The design and preparation of pharmaceutical co-crystals is a complex and multistage process, represented schematically in Figure 4. Co-crystal designing can be

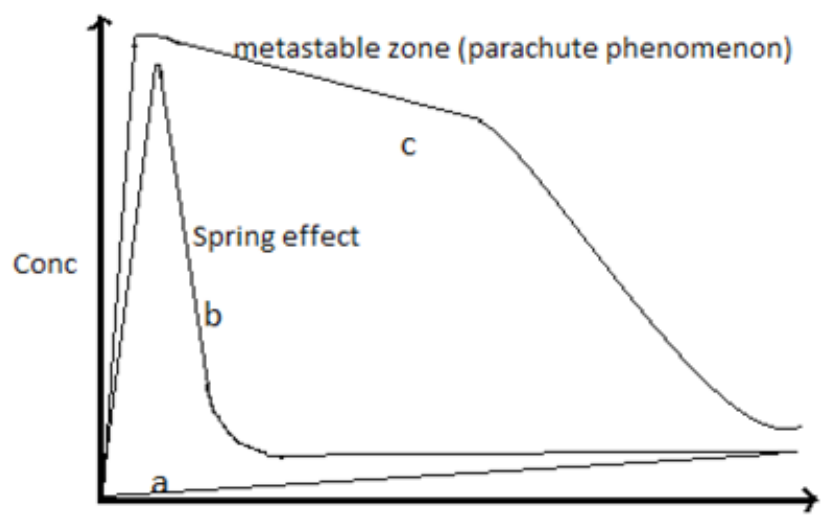

Time

Figure 3: Spring and parachute effect to attain high solubility for insoluble drug. a) Low soluble crystalline form. b) Amorphous phase (spring form) which is short lived meta stable state shows high solubility but drops quickly to crystalline form. c) Spring with parachute effect maintained metastable state for long time results in high soluble drug form.

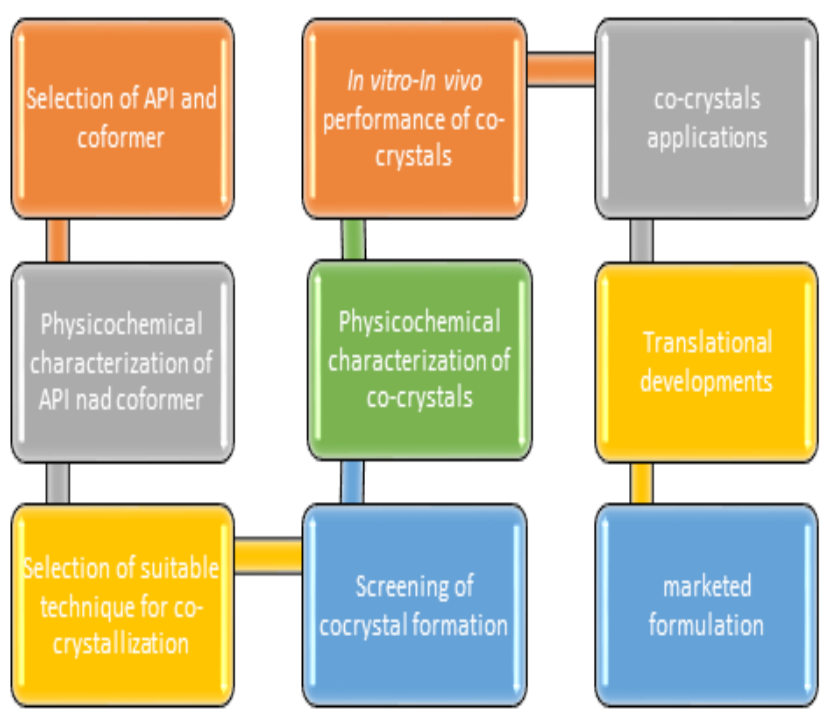

Figure 4: Design strategy involved in co-crystal formulation. 
done by empirical understanding of hydrogen-bonds pattern. ${ }^{76,77}$ The rules are (a) Crystal structure of a compound utilizes all the acidic hydrogens in the molecule for hydrogen bonding. (b) The availability of hydrogen bond donors leads to the utilization of good acceptors on hydrogen bonding. (c) Preferential formation of hydrogen bonds takes place between good donors and acceptors. N-H...O, N-H...Cl, N-H...H are some of the groups which can lead to the formation of hydrogen bonds. During designing of co-crystals, many worthful reference resources are containing empirical as well as theoretical resources such as CDS, HSP, Hydrogen bond theories and other empirical conclusions.

\section{Cambridge structural database}

Proper knowledge of intermolecular interactions is required for the synthesis of supramolecular synthons. Designing of synthons can be done by utilizing the information about hydrogen bond patterns of crystal lattice $^{78}$ which can be done by CSD. Intermolecular interactions on crystals can be studied by using which provides the information for systematic analysis of a wide range of related structures which could not be done by other methods. ${ }^{79}$ CSD contains information about the functional groups that result in the formation of supramolecular synthons. ${ }^{80}$

\section{Hansen solubility parameter}

Prediction of co-crystal formation by using Hansen solubility parameter was reported by Mohammad M A. ${ }^{81}$ This concept was actually proposed by Hansen C $\mathrm{M}$ for polymer solubility prediction in paints. HSP indicates that several individual forces compose the total energy of vaporization. ${ }^{82}$ The co-crystal formation can be predicted by calculating the difference in total solubility parameter $(\Delta \delta \mathrm{t})$ for API and co-former. These $\Delta \delta \mathrm{t}$ values more than $10 \mathrm{MP}^{0.5}$ indicates fewer chances for the co-crystal formation and less than $7 \mathrm{MP}^{0.5}$ indicates more co-crystal formation. ${ }^{80}$

\section{Co-crystallization techniques}

Co-crystallization technique, capable to amalgamate two or more molecules (API and conformer through non-covalent interaction and multiple API co-crystals through drug-drug interactions). Co-crystallization technique selection is the most important as the nature, properties and morphology of co-crystals formed were influenced by this process. ${ }^{70,83}$ Co-crystallization methods based on the use of solvents, classified as solventbased and solvent-free techniques. Among these, solvent free techniques are gaining more importance due to the possibility of a green chemistry principle association. ${ }^{84}$ Several aspects like API and co-former, solubility, stabil- ity, liability, polymorphs, solvents, etc were taken into consideration while selecting co-crystallization method. Method scalability should also be considered for applications in the industry. ${ }^{85}$

Depending on the driving force, the co-crystallization method can be classified as thermodynamic and kinetic methods. Thermodynamic methods occur mainly in equilibrium conditions and take a large amount of time to finish. Some of them are co-crystallization from melting and slow solvent evaporation. For kinetic methods, occur in non-equilibrium conditions based on reaction duration and system energy. This gives rise to metastable form, having higher gives free energy. Grinding, slurry sonication, supercritical fluid technology, spray drying is some of the techniques classified under kinetic methods. Co-crystallization methods based on the use of solvents classified as solvent-based and solvent-free techniques.

\section{Solvent based co-crystallization methods}

Solvent-based methods are most commonly used due to the ability to monitoring the process and controlling the properties of the final product. Solvent selection places the most crucial step in these methods. As the solvent selected shows its impact on crystal size, shape, purity, polymorphic form and other co-crystal characteristics. ${ }^{86,87}$ Some of the literatures reported the importance of solvent selection in solvent-based co-crystallization method. ${ }^{88,89}$ Solvent evaporation, cooling co-crystallization, reaction crystallization, anti-solvent addition, ultrasound-assisted co-crystallization are some of the examples comes under this method.

\section{Solvent free co-crystallization methods}

Solvent free co-crystallization methods are acquiring an interest in the industry and academia, due to the feasibility of being kindred with green chemistry principles. ${ }^{79}$ These principles endorse efficient co-crystal production with less toxic bi-products. Mechano-chemical methods, neat grinding, liquid assistant grinding, polymer assistant grinding, hot-melt extrusion, spray congealing co-crystallization are some of the methods classified under solvent-free co-crystallization. Some of the co-crystallization techniques reported were summarized in Table $2 .{ }^{90-115}$ Some of the latest international patents were summarized in Table 3. ${ }^{116-119}$

There is huge number of co-crystallization techniques, among which solvent-based methods are the most commonly used due to apparatus simplicity and procedures. But they have many unfavourable circumstances due to the use of hazardous solvents and dissimilar solubilities 
Table 2: Summary of reported co-crystallization techniques.

\begin{tabular}{|c|c|c|c|}
\hline Co-crystallization technique & Drug & Co-former & References \\
\hline \multirow{10}{*}{ Solvent evaporation } & Adefovir dipivoxil & Suberic acid and succinic acid & 90 \\
\hline & Ezetimibe & Benzoic acid and salicylic acid & 91 \\
\hline & Ketoconazole & Nicotinamide and 4-amino benzoic acid & 92 \\
\hline & Carbamazepine & nicotinamide & 93 \\
\hline & Mirtazapine & Oxalic acid & 94 \\
\hline & Fluoxetine hydrochloride & $\begin{array}{l}\text { Benzoic acid } \\
\text { salicylic acid } \\
\text { fumaric acid }\end{array}$ & 59 \\
\hline & Ibuprofen & 4,4-Dipyridyl Nicotinamide & 95 \\
\hline & Itraconazole & $\begin{array}{l}\text { Malic acid } \\
\text { Tartaric acid } \\
\text { Succinic acid }\end{array}$ & 62 \\
\hline & Norfloxacin & $\begin{array}{l}\text { Isonicotinamide } \\
\text { Succinic acid } \\
\text { Malonic acid } \\
\text { Maleic acid }\end{array}$ & 96 \\
\hline & Agomelatine & $\begin{array}{c}\text { Urea } \\
\text { Glycolic acid } \\
\text { Isonicotinamide } \\
\text { Methyl 4-hydroxybenzoate }\end{array}$ & 97 \\
\hline Solvent exchange method & Aceclofenac & chitosan & 98 \\
\hline Solvent assisted grinding & Hydrochlorothiazide & Aerosil & 99 \\
\hline Sonic slurry method & Carbamazepine & $\begin{array}{l}\text { Saccharin } \\
\text { nicotinamide }\end{array}$ & 100 \\
\hline Solvent drop grinding method & Diflunisal and diclofenac & Theophylline & 101 \\
\hline Liquid assisted grinding & Lomoxicam & $\begin{array}{l}\text { Catechol, resorcinol, benzoic acid, } \\
\text { hydroxyquinone and } 2,4 \text { dihydroxy } \\
\text { benzoic acid }\end{array}$ & 102 \\
\hline Dry grinding & Paracetamol & Trimethylglycine & 103 \\
\hline Solution crystallization & Febuxostat & $\begin{array}{l}\text { Urea, nicotinamide, acetamide, p-amino } \\
\text { benzoic acid, saccharine }\end{array}$ & 104 \\
\hline Slurry method & Quercetin & Caffeine, isonicotinamide, theobromine & 105 \\
\hline Solvent change method & Irbesartan & Chitosan & 106 \\
\hline Liquid assisted grinding & Curcumin & Resorcinol and pyrogallol & 107 \\
\hline Solvent assisted grinding & Indomethacin & Saccharin & 49 \\
\hline $\begin{array}{c}\text { Neat grinding, slow evaporation and wet } \\
\text { granulation }\end{array}$ & Niclosamide & $\begin{array}{l}\text { Caffeine, urea, theophylline, para } \\
\text { amino benzoic acid, nicotinamide, } \\
\text { isonicotinamide }\end{array}$ & 108 \\
\hline $\begin{array}{l}\text { Solution, slurry and solvent drop grinding } \\
\text { method }\end{array}$ & Meloxicam & Aspirin & 109 \\
\hline Spray drying technique & Efavirenz & Glutaric acid & 110 \\
\hline $\begin{array}{l}\text { Supercritical fluid enhanced atomization } \\
\text { technique }\end{array}$ & $\begin{array}{l}\text { Theophylline, Indomethacin, } \\
\text { Caffeine, Sulfamethazine, } \\
\text { Aspirin, Carbamazepine }\end{array}$ & Succinic acid & 111 \\
\hline Sublimation method & Urea & Succinic acid & 112 \\
\hline \multirow[t]{2}{*}{ Electrospray technology } & Carbamazepine & Nicotinamide & \multirow[t]{2}{*}{113} \\
\hline & Itraconazole & $\begin{array}{l}\text { Fumaric acid, } \\
\text { Succinic acid }\end{array}$ & \\
\hline Solvent evaporation & Glibenclamide & Tromethamine & 114 \\
\hline Hot melt extrusion & Carbamazepine & Soluplus $®$ & 115 \\
\hline
\end{tabular}




\begin{tabular}{|c|c|c|c|c|}
\hline \multicolumn{4}{|c|}{ Table 3: Latest international patents on cocrystals. } \\
\hline Date & Compounds & Assignee & Patent no. & Reference \\
\hline 9 Nov, 2017 & $\begin{array}{c}\text { dl - Proline and } \\
\text { Dapagliflozin }\end{array}$ & $\begin{array}{c}\text { Aurobindo } \\
\text { pharma limited }\end{array}$ & W02017191539A1 & 116 \\
\hline 31Aug, 2017 & $\begin{array}{c}\text { Lorcaserin hydrochloride } \\
\text { and organic diacid }\end{array}$ & Enantia, S. L & W02017172811A1 & 117 \\
\hline 6 Jul, 2017 & Adipic acid and agomelate & Leiutis pharmaceuticals Pvt, Ltd & W02017144598A1 & 118 \\
\hline 6 Oct, 2016 & Ibrutinib and carboxylic acid & Ratiopharm Gmbh & W02016156127A1 & 119 \\
\hline
\end{tabular}

of co-crystal components. Careful selection of methods is important for a specific system.

\section{Characterization and quality control}

Recent researches aimed at improving the storage stability, processing and dissolution of the pure drug during the development of pharmaceutical formulations. ${ }^{120,121}$ New regulatory guidelines from the FDA and EMA aimed at pharmaceutical co-crystal development, which should be facilitated with the requirements and approval procedures. ${ }^{122,123}$ Characterization and quality control of co-crystals were emphasized as important by these guidelines.

\section{Screening of co-crystal formation}

Liquid-assisted grinding has shown most attractive due to its short processing times, small sample sizes and a wide variety of applicable compounds. ${ }^{124}$ Its application to mixtures containing drug and possible co-formers results in systematic the screening of cocrystals. ${ }^{124}$ Thermal analysis and PXRD have been used during screening process for solids characterization. ${ }^{125}$ Faster detection of co-crystal formation can be done by Raman spectroscopy. ${ }^{126}$ Occurrence of new form at material interfaces can be shown by hot stage thermal microscopy. ${ }^{127}$ In-situ monitoring of co-crystal formation can be predicted based on appropriate co-former's selection and structural information. ${ }^{128,129}$

\section{Structural characterization}

Structure and physical properties determination are a critical step in understanding the quality of co-crystals developed. ${ }^{130,131}$ Several analytical techniques such as Raman spectroscopy, thermal analysis, solid-state NMR, $\mathrm{X}$-ray diffractions, etc., are used for these estimations. Single-crystal XRD technique provides the detailed crystal structure which in turn helps as the theoretical basis for quality control of co-crystals. Powder XRD data provide the structural information of co-crystals. ${ }^{132}$ Some co-crystals like caffeine/glutaric acid ${ }^{133}$ and carbamazepine/melonic acid ${ }^{134}$ results in multiple co-crystals or polymorphs based on preparation methods and formulation parameters. Some of the co-formers with multiple functional groups results in the formation of multiple hydrogen bonds, which leads to varied stacking arrangement in the crystal lattice. ${ }^{135}$ The state of carboxylic groups was evaluated by using FT-IR vibrational spectroscopy. ${ }^{136}$ Neutron diffraction provides the precise information of proton transfer within multi-component co-crystal. ${ }^{136,137}$ Cross polarization magic angle spinning provides a more practical characterization which was a new data processing method associated with solid-state NMR. ${ }^{138}$ X-ray photo electron spectroscopy and Raman spectroscopy mixed with density functional theories of solid-state were also being used for characterizations. ${ }^{139}$ Yong Du, conducted a series of investigations on structural characterization of different co-crystals during their formation by using vibrational spectroscopy. These studies reported Raman and terahertz technique as a unique means for co-crystal conformation and reaction dynamics during formation, ${ }^{140}$ FT-IR and FT-Raman could provide a theoretical and experimental standard to co-crystal characterization, ${ }^{141}$ Terahertz absorption and Raman scattering spectroscopy are able to identify the co-crystal structure and also $\mathrm{pH}$-dependent co-crystallization effect, ${ }^{142}$ Terahertz time-domain spectroscopy and Raman spectroscopy could be able to identify molecular structural change of drug and also intermolecular hydrogen bonds interactions upon co-crystallization. ${ }^{143} \mathrm{Co}$-crystals which were prepared by various techniques may contain a difference in their physical state, composition and productionrelated impurities. Due to this complexity, the quality maintenance of pharmaceutical co-crystal requires appropriate characterization methods.

\section{Characterization of physicochemical properties}

Product quality mainly depends on the physical properties of co-crystals can be known by multiple characterization methods. ${ }^{43}$ Melting temperature, thermal transition crystallinity, hydrate or solvate formation information can be provided by Thermal Gravimetry (TG) and differential scanning calorimetry. ${ }^{135,144}$ Most of the co-crystal contains the melting point different from their co-former and API's. Thermal scans using 
PXRD or DSC-PXRD can identify physical changes caused during measurements. Chemical analysis of thermally altered compounds can be elucidated by HPLC, FT-IR and Raman. Solvate or hydrate characterization can be done by residual water measurement and thermal gravimetry. ${ }^{43,135}$ Co-crystal stability can be assessed by measuring crystallinity. ${ }^{145}$ Crystallinity of CBZ/Saccharin and Indomethacin/Saccharin co-crystals can be provided by PXRD patterns and melting enthalpy. ${ }^{146}$

\section{In vitro and in vivo performance of co-crystals}

Solubility and dissolution profiles of low soluble API's are improved by co-crystal formation. ${ }^{147}$ The in vivo bioavailability of low soluble API's is also improved in animal models. ${ }^{27,41}$ Shake - Flask method is mainly used for the evaluation of solubility of API at a given temperature in a given media. ${ }^{67,148}$ In vitro characterization are conducted by the measurements of intrinsic dissolution rates. ${ }^{149,150}$ Intrinsic dissolution rate is often a good parameter for predicting the in vivo performance of API. ${ }^{59}$ Animal studies will give the information about the behaviour of the formulation. It was proved that the high concentration in the main absorption region improves the bioavailability of low soluble API's in many of co-crystal. ${ }^{27,50,151}$ This animal study data should be evaluated carefully for the relevance to humans. Feeding conditions also influence the solubility and bioavailability of co-crystals formed. ${ }^{152}$

It is significant to mention that no single technique is sufficient to characterize completely the co-crystal structure and properties. Various characterization techniques integration can help to characterize or elucidate the structure and properties of co-crystalline materials. Among all the techniques vibrational spectroscopic techniques seem to be more beneficial for elucidation and characterization.

\section{Challenges involved in translational development of co-crystals}

Any drug substance, for converting into the drug product consists of pre formulation studies, prototype formulation, development of process, scale up and finally manufacturing of batches. The unique properties and structural features of co-crystals remain as challenging for developing them into drug product. These challenges can be reduced by selecting suitable co-crystal for the development. Translational development of cocrystals is a complex process, represented schematically in Figure 5.

\section{Excipient selection}

Selecting of compatible excipient is an utmost important step of the pre-formulation activity. The overall

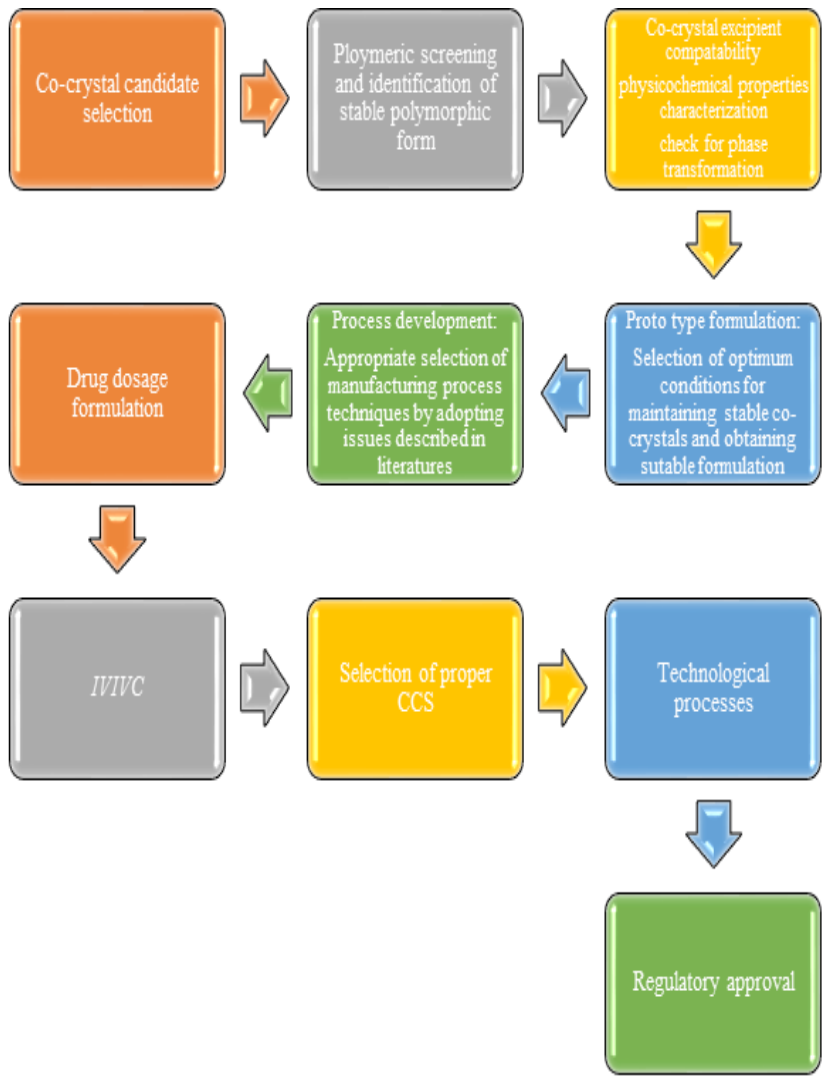

Figure 5: Schematic representation involved in translational development of co-crystals.

performance of the drug product mainly depends on the selected excipients. ${ }^{153}$ Alhalaweh, 2014 conducted studies on celecoxib-nicotinamide co-crystals with different concentrations of SLS and polyvinyl pyrrolidone polymer, reported with the increase in bioavailability of formulation containing 1-10\% of SLS and polyvinyl pyrrolidone. The author reported the importance of use in suitable concentration of surfactant (SLS) or polymer (PVP), which in turn decreases the chance of phase transformation and increase solubility. ${ }^{154}$ Childs, 2013 prepared DNZ-VAN co-crystal. This formation contains $1 \% \mathrm{D}$ - $\alpha$-tocopherol polyethylene glycol succinate as solubilizer and 2\% Kluce LF pharma hydroxy propyl cellulose as crystallization inhibitor. This formulation showed 10-fold increase of AUC (Area under curve) when compared to parent DNZ. Whereas nonformulated DNZ co-crystals showed a modest increase of 1.7 times higher AUC in comparison with parent molecule. ${ }^{75}$ Some literatures reported the role of additives on co-crystal performance. ${ }^{155-158}$ Maintenance of parachute condition (prevention of supersaturation triggered precipitation) of a drug is an important aspect for co-crystal-based products. This can be achieved by selecting a polymer based on their precipitation inhibitor capacity of co-crystal and drug.75,155-156 Selection 
of suitable surfactant with optimal concentration will prevent the solution mediated transformation ${ }^{64,159}$ and maximum apparent solubility. ${ }^{75}$

\section{Prototype formulation}

The aim of formulation development is to investigate the impact of excipients on the performance, manufacturability and safety of the product. Co-crystal eutectic constant $\mathrm{K}_{\mathrm{eu}}$ and identification of different parameter at transition point, plays a major role in the selection and optimization of suitable excipients. ${ }^{64,154,160,161}$ Selection of optimal $\mathrm{pH}$ is a crucial parameter to gain maximum solubility. ${ }^{162}$ Normally a formulation contains diverse excipients and the effect of these excipients on product performance should be investigated by using sound statistical experiments. Constituting in vitro - in vivo correlation is the major challenging aspect in co-crystal product development. In vitro performance of the product may be hardly correlated with in vivo performance due to changes in the micro environment $\mathrm{p}^{\mathrm{H}}$, presence of endogenous surfactants, Lipids etc. which may alter the solubility of the product. Cheney, 2009 conducted, in vitro and in vivo studies of lamotrigine co-crystals with NCT. This formulation showed an enhanced dissolution rate, whereas decreased oral bio availability in rats when compared to parent molecules. ${ }^{163}$ Establishing an appropriate formulation strategy will help in obtaining desired mechanical properties and also minimizes phase transformation of co-crystals during mechanical stress. Previous literatures stated that some of the co-crystals may undergo polymorphic phase transformation due to mechanical stress. ${ }^{164}$ Cushioning agents like carrageenan's, alginates, chitosan's, polyethylene oxides and microcrystalline cellulose pellets may avoid the compaction induced phase transformation by absorbing the mechanical shock in tablet formulation. ${ }^{165,166}$

\section{Process development}

Process development is aimed at identifying the critical process parameters for ensuring the quality of the product. The selection of equipment, in-process controls and manufacturing process depends on the material properties of co-crystals. Dissociation of Theophylline co-crystals with acidic co-formers like malonic, glutaric or maleic acids will take place in the presence of water. ${ }^{53}$ Likewise, wet granulation and wet milling operations may result in dissociation of co-crystals. ${ }^{167} \mathrm{So}$, the selection of alternative operations like dry granulation and dry milling may be beneficial in these situations. Anhydrous THP-Citric acid co-crystals were converted to co-crystal hydrates within 3 days when maintained in humidity conditions. ${ }^{168}$ This problem can be rectified by maintaining low humidity during manufacturing.
Sodium naproxen -lactose-tetrahydrate co-crystals when heated from $60^{\circ} \mathrm{C}$ to $120^{\circ} \mathrm{C}$, results in loss of water molecules from crystal lattice and transformed to coamorphous form. ${ }^{169}$ Therefore, adoption of the issues described in the literature should be done while selecting the manufacturing process. ${ }^{170}$ Zhou, 2016 reported the improved solubility and tabletability of Resveratrol co-crystals, these cocrystals also shown the non-hygroscopic and phase stable even in high humid conditions, which makes them suitable for tablet formulation. ${ }^{171}$

\section{Container closure systems (CCS)}

The choice of selecting proper packing should be based on the nature of co-crystals and resistance against stressors. Optimized CCS can help in protecting the product against moisture, light and oxygen. AMG517: 2-hydroxy caproic acid co-crystals showed slight hygroscopic nature at $8 \% \mathrm{RH} / 25^{\circ} \mathrm{C}$, during moisture absorption studies. ${ }^{21}$ This problem can be rectified by adopting, humidity control, water-free process of manufacturing area and by protective packing. The selection of proper CCS may overcome some of the challenges regarding the transitional development of co-crystals. More studies should be required in this aspect.

Even though rational formulation, environment control, proper process development and selection of ccs may overcome the translational challenges of co-crystals, it is recommended to choose the most suitable co-crystal candidate for pre-formulation screening

\section{Applications}

The strategy of converting the idea of co-crystals into the application was already described in the translational development challenges of this paper.

Apixaban (AXP, trade name Eliquis ${ }^{\circledR}$ ). Which could be used in various thromboembolic treatment after knee or hip replacement surgery, ${ }^{172,173}$ having poor solubility and low oral bioavailability. There is no improvement in oral bioavailability even increasing the dose more than $25 \mathrm{mg}$, which is the goal for improving the solubility. ${ }^{174,175} \mathrm{Chen}$ and co-workers prepared APX: oxalic acid co-crystals. Which results in better solubility when compared with anhydrous APX form. The pharmacokinetic studies of APX-OXC co-crystals shoed 2.7 times larger $\mathrm{AUC}_{0-} 24 \mathrm{~h} .{ }^{175}$

Adefovir dipivoxil (AD, trade name Hepsera ${ }^{\circledR}$ ) used against the hepatitis $\mathrm{B}$ virus. The drug is thermally unstable $^{176}$ and the degradation was accelerated by many factors. ${ }^{176-178}$ The marketed formulation remains stable at room temperature ${ }^{179}$ and converted to dehydrate form at $75 \% \mathrm{RH}$ conditions. ${ }^{180}$ Jung $\mathrm{S}$ prepared AD co-crystals with suberic acid and succinic acid as 
co-formers, the thermal stability and aqueous solubility were improved in both the cases. ${ }^{181}$ AD: Saccharine cocrystals maintained their stability throughout the storage conditions ( 1 month) at $60^{\circ} \mathrm{C} .^{182}$ These studies help in the implication of the co-crystallization approach to unstable drugs and can result in longer expiry dated preparations.

P-Hydroxyacetanilide (paracetamol PA) is the most popular API used as analgesic ${ }^{183,184}$ which exhibits poor compatibility and belongs to BCS Class-III. ${ }^{185}$ PA cocrystals formed with different co-formers PA- Pherazine, ${ }^{186}$ PA-trimethyl glycine, ${ }^{187}$ PA-citric acid ${ }^{188}$ and others $^{189}$ results in improved physiochemical, mechanical and pharmaceutical properties.

Ethenzamide (2-etoxy benzamide, ET) is a commonly used non-steroidal anti-inflammatory drug belongs to BCS Class-II, whose water solubility is low and some of the modifications may improve the property. ${ }^{190-192}$ Many of the literatures proved that the co-crystals of ET with different co-formers showed improvement in solubility and other physicochemical properties. ${ }^{193,194}$
Hexamethylene bis-acetamide $\mathrm{A}$ is an anticancer drug used in lung cancer treatment. ${ }^{195,196}$ Aakeroy prepared the co-crystals of Hexamethylene bis-acetamide A with a dicarboxylic acid. These co-crystals have the melting point in a range of $148^{\circ} \mathrm{C}-188^{\circ} \mathrm{C}$ whereas API melting point ranges between $181^{\circ} \mathrm{C}-182^{\circ} \mathrm{C}$. Solubility studies showed improvement by a factor of 2.5 when compared to API. ${ }^{197}$

Isoniazid (INH) which is the first-generation antitubercular drug ${ }^{198}$ has been reported with high solubility, whereas chemical stability in tablets is very low. ${ }^{199}$ Many of the co-crystals such as INH: Fumaric acid, ${ }^{200}$ INH: caffeine acid, ${ }^{201}$ INH: Sebacic acid ${ }^{202}$ and many other co-formers are used for INH co-crystals such as Nicotinamide, succinic acid, vanilic acid, ferulic acid, etc preparation of co-crystals act as potential drug modification for solid drug formulation. ${ }^{200}$

Formation of drug-drug pharmaceutical co-crystals results to overcome the problems related with a traditional combination of drugs by modifying the properties of both drugs. ${ }^{59,198,203}$ Telmisartan: Atenolol

\begin{tabular}{|c|c|c|c|}
\hline Pharmaceutical co-crystal & components & Indication & Status or Source \\
\hline Beta-Chlor ${ }^{\circledR}$ & Chloral hydrate... betaine & Sedation & Approved by FDA on 1963 \\
\hline Depakote $^{\circledR}$ & Valproic acid... [valproate sodium] & Epilepsy & Approved by FDA on 1983 \\
\hline Cafcit $^{\circledR}$ & Caffeine... [citric acid] & Infantile apnoea & Approved by FDA on 1999 \\
\hline Lexapro $^{\circledR}$ & $\begin{array}{c}\text { [Escitalopram oxalate] ... Oxalic } \\
\text { acid }\end{array}$ & Depression & Approved by FDA on 2002 \\
\hline Suglat ${ }^{\circledR}$ & Ipragliflozin... L-proline & Diabetes & Approved by FDA on 2014 \\
\hline Entresto $^{\circledR}$ & $\begin{array}{c}\text { [Valsartan sodium] ... [sacubitril } \\
\text { sodium] }\end{array}$ & Heart failure & Approved by FDA on 2015 \\
\hline Odomzo $^{\circledR}$ & $\begin{array}{c}\text { [Sonidegib monophosphate]... } \\
\text { phosphoric acid }\end{array}$ & Basal cell carcinoma & Approved by FDA on 2015 \\
\hline Steglatro $^{\circledR}$ & Ertugliflozin... L-pyroglutamic acid & Diabetes & Approved by FDA on 2017 \\
\hline Dichloralphenazone & Antipyrine... Chloral hydrate & Migrain & PubChem CID 10188 \\
\hline Iron sorbitex & Iron... Sorbital... Sodium citrate & Iron deficiency anaemia & PubChem CID 20715017 \\
\hline Nicotinamide-ascorbic acid & Nicotinamide... ascorbic acid & Vitamin complex & PubChem CID 54710212 \\
\hline Tetracycline phosphate & Tetracycline... phosphoric acid & Antibiotic & PubChem CID 54713149 \\
\hline Caffeine-sodium benzoate & Caffeine... sodium benzoate & Headache & $\begin{array}{c}\text { British Pharmaceutical Codex } \\
1907\end{array}$ \\
\hline Caffeine-sodium salicylate & Caffeine... sodium salicylate & Headache & $\begin{array}{c}\text { British Pharmaceutical Codex } \\
1907\end{array}$ \\
\hline Acridine-sulfonamide & Acridine... sulfonamide & Antiseptic & PubChem CID 54710212 \\
\hline TAK-020 & TAK-020... gentisic acid & $\begin{array}{c}\text { Bruton tyrosine kinase } \\
\text { inhibitor }\end{array}$ & $\begin{array}{l}\text { Under Phase-I Clinical trial } \\
\text { Identifier- NCT02723201 }\end{array}$ \\
\hline E-58425 & Tramadol hydrochloride... celecoxib & NSAID & $\begin{array}{l}\text { Under Phase-III Clinical trial } \\
\text { Identifier- NCT03108482 }\end{array}$ \\
\hline CC-31244 & $\begin{array}{l}\text { Non-nucleoside polymerase } \\
\text { inhibitor }\end{array}$ & $\begin{array}{l}\text { Non-nucleoside } \\
\text { polymerase inhibitor }\end{array}$ & $\begin{array}{l}\text { Under Phase-Ila Clinical trial } \\
\text { Identifier- NCT0276075 }\end{array}$ \\
\hline T121E01F/T121E02F & Zoledronic acid co-crystals & Anticancer & $\begin{array}{l}\text { Under Phase I Clinical trial } \\
\text { Identifier- NCT01721993 }\end{array}$ \\
\hline
\end{tabular}


co-crystals ${ }^{204}$ proved that multidrug co-crystals could be a great replacement for standard therapy with more than one API. Almansa prepared tramadol hydrochloride: celecoxib co-crystals which showed favourable physicochemical and dissolution profiles. ${ }^{205}$ These cocrystals completed their phase-I and phase-II clinical studies whereas phase-III is going on. ${ }^{206}$

\section{Commercial co-crystal formulations}

Beta-Chlor ${ }^{\circledR}$ (chloral betaine), US patent described its formulation in 1962, as its aim was to mask the unpleasant taste of chloral ${ }^{207}$ but its co-crystal structure was revealed in 2016. ${ }^{193}$ Zaworot Ko described chloral betain as charge assisted diol-carboxylate heterodimer. These co-crystals showed increased thermal stability when compared to pure drug. ${ }^{208}$

Depakene $^{\circledR}$ (Valproate semi sodium) Valproate showed full potential in the treatment and prevention of scissors. ${ }^{209}$ This is presently sold in 3 forms. Valproate: Valproic acid (free acid, trade name Depakote ${ }^{\circledR}$ ), sodium valproate (salt, trade name Epilim $^{\circledR}$ ) and semisodium Valproate (co-crystal, trade name Depakene ${ }^{\mathbb{B}}$ ). ${ }^{210}$ Of all the several forms of valproate, the co-crystal formulation showed the superior physicochemical properties, mainly by decreasing the hygroscopicity which was found in other forms. ${ }^{211}$

Cafcit $^{\circledR}$ (Caffeine citrate) According to British pharmaceutical codex 1907, caffeine citrate exhibits high stability in concentrated solution than pure alkaloid (pharmaceutical codex 1907). Karki, in his studies, revealed the co-crystal structure of caffeine citrate in 2007, which was previously known as complex. ${ }^{168}$

Lexapro $^{\circledR}$ (Escitalopram oxalate) It is marketed as cocrystal which contains escitalopram oxalate salt and oxalic acid, where citalopram as hydrobromide salt, which leads to controversies regarding structural enantiomers. ${ }^{212}$ Harrison demonstrated the patentable cocrystal from this formulation ${ }^{213}$ recently, the Lanset reported, Escitalopram, vortioxetine is agomelatine are the most effectual antidepressants available. ${ }^{214}$ Some of the pharmaceutical co-crystal products were summarised in Table 4

Successful drug delivery may be possible with co-crystallization. The life time of API could be enhanced through co-crystallization, further drug-drug co-crystals may be helpful to increase therapeutic efficacy by combinational therapy. Inturn, co-crystallization also enhances the chance of tablatability, stability and physicochemical properties as discussed under previous sections.

\section{CONCLUSION}

The requirement in drug properties modification is the main reason for gaining extensive attention on cocrystals. The improvement in dissolution rate, bioavailability, solubility and other physicochemical properties has been reported frequently. Research should centre in actual industry problems, such as the scaleup method for industrial standards and high throughput screening methods. Method selection is immensely important and particular for each system. A great effort is required in order to apply co-crystallization in the pharmaceutical industry as a customary method to improve drug properties. Preclinical and clinical studies have confirmed a proof-of-concept on the benefit of co-crystals. However, co-crystals may phase notable challenges in their translation to drug products. This includes co-former safety, polymorphism, lower than super saturation solubility, the behaviour of co-crystal in formulation and difficulty in conducting an IVIVC. An increase in scientific knowledge on crystal engineering and biopharmaceutical performance of co-crystals shall lead to the introduction of drug products containing co-crystals.

\section{ACKNOWLEDGEMENT}

The authors wish to thank Maharajah's College of Pharmacy, Vizianagaram and Gitam Institute of Pharmacy, (Deemed to be university), Visakhapatnam for providing their support and continuous encouragement during the preparation of this review paper.

\section{CONFLICT OF INTEREST}

The authors declare no conflicts of interest.

\section{ABBREVIATIONS}

API: Active pharmaceutical ingredient; EMA: European medicine agency; FDA: Food Drug Administration; RH: Relative humidity; HPLC: High performance liquid chromatography; Hcl: Hydrochloric acid; Keu: eutectic constant; TPGS: D- $\alpha$-Tocopheryl polyethylene glycol 1000 succinate; BCS: Biopharmaceutical classification system; CDS: Cambridge structural database; HSP: Hansen solubility parameter; PXRD: Powder x-ray diffraction; XRD: X-ray powder diffraction; NMR: Nuclear magnetic resonance; FT-IR: Fourier transform infrared spectroscopy; DSC: Differential scanning calorimetry; CBZ: Carbamazepine; SLS: Sodium lauryl sulphate; PVP: Polyvinyl pyrrolidone; DNZ: Danazol; VAN: Vanillin; AUC: Area under curve; NCT: Nicotinamide; TPH: Theophyl- 
line; CCS: Container closure systems; APX: Apixaban; OXC: Oxalic acid; AD: Adefovir dipivoxil; INH: Isoniazid; IVIVC: In vivo - in vitro correlation.

\section{REFERENCES}

1. Chow K, Tong HHY, Lum S, Chow AHL. Engineering of pharmaceutical materials: An industrial perspective. J Pharm Sci. 2008;97(8):2855-77.

2. Yamamoto K, Kojima T, Karashima M, Ikeda Y. Pharmaceutical evaluation and developability assessment of co-amorphouses of low soluble drugs and comparison to the co-crystals. Chem Pharm Bull. 2016;64(12):1739-46.

3. Blagden N, DeMatas M, Gavan PT, York P. Crystal engineering of active pharmaceutical ingredients to improve solubility and dissolution rates. Adv Drug Del Rev. 2007;59(7):617-30.

4. Zhi HL, Asim KS, Paul WSH. Overview of milling techniques for improving the solubility of poorly water-soluble drugs. Asian J Pharm Sci. 2015;10(4):25574.

5. Nannan G, Mengran G, Qiang F, Zhonggui H. Application of hot melt extrusion to enhance the dissolution and oral bioavailability of oleanolic acid. Asian J Pharm Sci. 2017;12(1):66-76.

6. Nitin PG, Panchaxari MD, Anand PG, Vinayak SM. Solubility Enhancement of Satranidazole Using Self Emulsified Drug Delivery Systems. IJPER. 2016;50(3):S68-75.

7. Kulthe VV, Chaudhari PD. Solubility Enhancement of Etoricoxib by Solid Dispersions Prepared by Spray Drying Technique. IJPER. 2011;45(3):24858.

8. Apichart A, Somchai S. Inclusion complexes between sildenafil citrate and cyclodextrins enhance drug solubility. Asian J Pharm Sci. 2016;11(1):104-5.

9. Srinivas L, Venkata SVKT, Sunil KN. Design and Development of Vancomycin Liposomes. IJPER. 2015;49(3):208-15.

10. Kanokporn B, Hirofumi T, Pornsak S. Development of pectin nanoparticles through mechanical homogenization for dissolution enhancement of itraconazole. Asian J Pharm Sci. 2016;11(3):365-75.

11. Schultheiss N, Newman A. Pharmaceutical cocrystals and their physicochemical properties. Cryst Growth Des. 2009;9(6):2950-67.

12. Douroumis SA, Ross A, Nokhodchi. Advanced methodologies for cocrystal synthesis. Adv Drug Deliv Rev. 2017;117:178-95.

13. Regulatory Classification of Pharmaceutical Co-Crystals Guidance for Industry. FDA Guidance. 2018;1-7. https://www.fda.gov/downloads/drugs/ guidances/ucm281764.pdf.

14. Shete AS, Yadav AV, Murthy MS. Enhancement of Dissolution Rate of Irbesartan by Chitosan based Crystal Engineering Technique. IJPER. 2012;46(4):323-9.

15. Amol SS, Vishwajeet VK, Srinivasa MM, Adhikrao VY, Sfurti SS, Rajendra CD. Solid State Characterization and Tableting Studies of Ethanol Based Cocrystals of Fenofibrate with Nicotinamide. IJPER. 2018;52(1):71-7.

16. Lu E, Rodriguez-Hornedo N, Suryanarayanan R. A rapid thermal method for cocrystal screening. Cryst Engcomm. 2008;10(6):665-8.

17. Aher S, Dhumal R, Mahadik K, Paradkar A, York P. Ultrasound assisted cocrystallization from solution (USSC) containing a non-congruently soluble cocrystal component pair: Caffeine/maleic acid. Eur J Pharm Sci. 2010;41(5):597-602.

18. Friscic $\mathrm{T}$, Jones $\mathrm{W}$. Recent advances in understanding the mechanism of cocrystal formation via grinding. Cryst Growth. 2009;9(3):1621-37. Miroshnyk I, Mirza S, Sandler N. Pharmaceutical co-crystals-an opportunity for drug product enhancement. Expert Opin Drug Deliv 2009;6(4):333-41.

19. Fernandes GJ, Kumar L, Sharma K, Tunge R, Rathnanand M. A review on solubility enhancement of carvedilol - A BCS class II drug. J Pharm Innovation. 2018;13(3):197-212.

20. Miroshnyk I, Mirza S, Sandler N. Pharmaceutical co-crystals-an opportunity for drug product enhancement. Expert Opin Drug Deliv. 2009;6(4):333-41.

21. Stanton MK, Bak A. Physicochemical properties of pharmaceutical cocrystals: A case study of ten AMG 517 co-crystals. Cryst Growth Des. 2008;8(10):3856-62.
22. Rodrigues M, Baptista B, Lopes JA, Mafalda CS. Pharmaceutical cocrystallization techniques: Advances and challenges. Int $\mathrm{J}$ Pharm. 2018;547(1-2):404-20.

23. Dnyaneshwar PK, Sandeep SZ, Arvind KB. Challenges in translational development of pharmaceutical cocrystals. J Pharm Sci. 2016;10(21):1-14.

24. Ning S, Miranda LP, David RW, Michael JZ. Impact of pharmaceutical cocrystals: The effect on drug pharmacokinetics. Expert Opin Metab. 2014;10(9):1255-71.

25. Abhijeet SS, Anita RM, Simon EL. Recent review articles such as: Cocrystallization of Nutraceuticals. Crystal Growth Design. 2015;15(2):9841009.

26. Yong $D$, Jiadan $X$. Investigation of polymorphism and cocrystallization of active pharmaceutical ingredients using vibrational spectroscopic techniques. Curr Pharm Des. 2016;22(32):4917-28.

27. Bak A, Gore A, Yanez E, Stanton M, Tufekcic S, Syed R, et al. The co-crystal approach to improve the exposure of a water-insoluble compound: AMG 517 sorbic acid co-crystal characterization and pharmacokinetics. J Pharm Sci. 2008;97(9):3942-56.

28. Aakeroy CB, Fasulo ME, Desper J. Cocrystal or salt: Does it really matter? Mol Pharm. 2007;4(3):317-22.

29. Hemamalini M, Loh WS, Quah CK, Fun HK. Investigation of supramolecular synthons and structural characterisation of aminopyridine-carboxylic acid derivatives. Chem Cent J. 2014;8:1-9.

30. Desiraju GR. Sipramolecular synthons in crystal engineering - a new organic synthesis. Angewandte Chemie-International Edition in English. 1995;34(21):2311-27.

31. Izutsu KI, Koide T, Takata N, Ikeda Y, Ono M, Inoue M, et al. Characterization and Quality Control of Pharmaceutical Cocrystals. Chem Pharm Bull. 2016;64(10):1421-30.

32. Almarsson $\mathrm{O}$, Zaworotko MJ. Crystal engineering of the composition of pharmaceutical phases: Do pharmaceutical co-crystals represent a new path to improved medicines. Chem Commun. 2004;35(17):1889-96.

33. Khan M, Enkelmann V, Brunklaus G. Crystal engineering of pharmaceutical co-crystals: application of methylparaben as molecular hook. J Am Chem Soc. 2010;132(14):5254-63.

34. Karki S, Friscic T, Jones W. Control and interconversion of cocrystal stoichometry in grinding: stepwise mechanism for the formation of a hydrogen-bonded cocrystal. Crysteng Comm. 2009;11(3):470-81.

35. He GW, Jacob C, Guo LF, Chow PS, Tan RBH. Screening for cocrystallization tendency: The role of intermolecular interaction. J Phys Chem B. 2008;112(32):9890-5.

36. Bis JA, Vishweshwar P, Weyna D, Zaworotko MJ. Hierarchy of supramolecular synthons: Persistent hydroxyl pyridine hydrogen bonds in cocrystals that contain a cyano acceptor. Mol Pharmaceutics. 2007;4(3):401-16.

37. Vishweshwar P, McMahon JA, Bis JA, Zaworotko MA. Pharmaceutical cocrystals. J Pharm Sci. 2006;95:499-516.

38. Jones W, Motherwell WDS, Trask AV. Pharmaceutical co-crystals: An Emerging approach to physical property enhancement. MRS Bull. 2006;31(11):875-9.

39. Food and Drug Administration, F. Regulatory classification of Pharmaceutical co-crystals guidance for industry. 2016.

40. Cerreia VP, Chierotti MR, Gobetto R. Pharmaceutical aspects of salt and cocrystal forms of APIs and characterization challenges. Adv Drug Deliv Rev. 2017;117:86-110.

41. Bryn SR, Pfeiffer RR, Stowell JG. Solid-State Chemistry of Drugs. 2nd ed. West Lafayette: IN. 1999.

42. Blagden N, Berry DJ, Parkin A, Javed H, Ibrahim A, Gavan PT, et al. Current directions in co-crystal growth. New J Chem. 2008;32(10):1659-72.

43. Schultheiss N, Newman A. Pharmaceutical cocrystals and their physicochemical properties. Cryst Growth Des. 2009;9(6):2950-67.

44. Abramowitz R, Yalkowsky SH. Melting Point, Boiling Point and Symmetry. Pharm Res. 1990;7(9):942-47.

45. Burger A, Ramberger R. On the polymorphism of pharmaceuticals and other molecular crystals. I. Mikrochim Acta. 1979;72(3-4):259-71.

46. Aakeroy CB, Forbes S, Desper J. Using cocrystals to systematically modulate aqueous solubility and melting behavior of an anticancer drug. J Am Chem Soc. 2009;131(47):17048-9. 
47. Fleischman SG, Kuduva SS, McMahon JA, Moulton B, Bailey Walsh $\mathrm{RD}$, Rodri'guez-Hornedo N. Crystal Engineering of the Composition of Pharmaceutical Phases: Multiple-Component Crystalline Solids Involving Carbamazepine. J Cryst Growth Des. 2003;3(6):909-19.

48. Rolf $\mathrm{H}$. The Physical Characterization of Hygroscopicity in Pharmaceutical Solids, In Polymorphism. Wiley-VCH: Weinheim. 2006;235-58.

49. Basavoju S, Bostrom D, Velaga SP. Indomethacin-Saccharin Cocrystal: Design, Synthesis and Preliminary Pharmaceutical Characterization. Pharm Res. 2008;25(3):530-41.

50. McNamara DP, Childs SL, Giordano J, larriccio A, Cassidy J, She MS. Use of a glutaric acid cocrystal to improve oral bioavailability of a low solubility API. Pharm Res. 2006;23(8):1888-97.

51. Padrela L, Rodrigues MA, Velaga SP, Fernandes AC, Matos HA, DeAzevedo EG. Screening for pharmaceutical cocrystals using the supercritical fluid enhanced atomization process. J Supercrit Fluids. 2010;53(1-3):156-64.

52. Pop M, Sieger P, Cains P. Example: API/ fumerate/ fumaric acid. W J Pharm Sci. 2008;95:1820-34.

53. Trask AV, Motherwell S, Jones W. Pharmaceutical Cocrystallization: Engineering a Remedy for Caffeine Hydration. Cryst Growth Des. 2005;5(3):1013-21.

54. Oswald IDH, Allan DR, McGregor PA, Motherwell WDS, Parsons S, Pulham $\mathrm{CR}$. The formation of paracetamol (acetaminophen) adducts with hydrogenbond acceptors. Acta Crystallogr Sect B. 2002;58(Pt 6):1057-66.

55. Variankaval N, Wenslow R, Murry J, Hartman R, Helmy R, Kwong E. Preparation and Solid-State Characterization of Nonstoichiometric Cocrystals of a Phosphodiesterase-IV Inhibitor and L-TARTARIC ACID. Crystal Growth Des. 2006;6(3):690-700.

56. Chen AM, Ellison ME, Peresypkin A, Wenslow RM, Variankaval N, Savarin CG. Development of a pharmaceutical cocrystal of a monophosphate salt with phosphoric acid. Chem Commun. 2007;4(4):419-21.

57. Hickey M, Peterson M, Scoppettuolo L, Morrisette S, Vetter A, Guzmán H. Performance comparison of a co-crystal of carbamazepine with marketed product. European Journal of Pharmaceutics and Biopharmaceutics. 2007;67(1):112-9.

58. Childs SL, Rodriguez-Hornedo N, Reddy LS, Jayasankar A, Maheshwari $C$, McCausland L, et al. Screening strategies based on solubility and solution composition generate pharmaceutically acceptable cocrystals of carbamazepine. Cryst Eng Comm. 2008;10(7):856-64.

59. Childs SL, Chyall LJ, Dunlap JT, Smolenskaya VN, Stahly BC, Stahly GP. Crystal Engineering Approach to Forming Cocrystals of Amine Hydrochlorides with Organic Acids. Molecular Complexes of Fluoxetine Hydrochloride with Benzoic, Succinic and Fumaric Acids. J Am Chem Soc. 2004;126(41):1333542.

60. Hildebrand JH. Solubility: The Chemical Catalog Company: New York. $1924 ; 206$.

61. Hildebrand JH, Scott RL. The solubility of Nonelectrolytes. $3^{\text {rd }}$ ed. New York: Reinhold publishing. 1950;113(2938):450-1.

62. Remenar JF, Morissette SL, Peterson ML. Crystal engineering of novel co-crystals of a triazole drug with 1,4-dicarboxylic acids. J Am Chem Soc. 2003;125(28):8456-7.

63. Shiraki K, Takata N, Takano R. Dissolution improvement and the mechanism of the improvement from cocrystallization of poorly water-soluble compounds. Pharm. Res. 2008;25(11):2581-92.

64. Good DJ, Rodríguez-Hornedo N. Cocrystals eutectic constants and prediction of solubility behaviour. Cryst Growth Des. 2010;10(3):1028-32.

65. Luedeker D, Gossmann R, Langer K, Brunklaus G. Crystal engineering of pharmaceutical co-crystals: "NMR crystallography" of niclosamide cocrystals. Cryst Growth Des. 2016;16(6):3087-100.

66. Serajuddin ATM. Salt formation to improve drug solubility. Adv Drug Del Rev. 2007;59(7):603-16.

67. Good DJ, Rodríguez-Hornedo N. Solubility Advantage of Pharmaceutical Cocrystals. Cryst Growth Des. 2009;9(5):2252-64.

68. Liu R. Water-insoluble Drug Formulation. $2^{\text {nd }}$ ed. Boca Raton: CRC Press. 2008.

69. Yalkowsky SH. Solubility and Solubilization in Aqueous Media. American Chemical Society. New York: Oxford University Press: 1999. J Am Chem Soc. $2000 ; 122(40): 9882$.
70. Trask AV, Motherwell WDS, Jones W. Physical stability enhancement of theophylline via cocrystallization. Int J Pharm. 2006;320(1-2):114-23.

71. Guzmán HR, Tawa M, Zhang Z, Ratanabanangkoon P, Shaw P, Gardner $\mathrm{CR}$. Combined use of crystalline salt forms and precipitation inhibitors to improve oral absorption of celecoxib from solid oral formulations. J Pharm Sci. 2010;96(10):4215-27.

72. Friščić $T$, Jones $W$. Benefits of cocrystallisation in pharmaceutical materials science: An update. J Pharm Pharmacol. 2010;62(11):1547-59.

73. Brouwers J, Brewster ME, Augustijns P. Supersaturating drug delivery systems: the answer to solubility-limited oral bioavailability?. J Pharm Sci. 2009;98(8):2549-72.

74. Babu NJ, Nangia A. Solubility advantage of amorphous drugs and pharmaceutical cocrystals. Cryst Growth Des. 2011;11(7):2662-79.

75. Childs SL, Kandi P, Lingireddy SR. Formulation of a Danazol cocrystal with controlled supersaturation plays an essential role in improving bioavailability. Mol Pharm. 2013;10(8):3112-27.

76. Etter MC. Encoding and decoding hydrogen-bond patterns of oganic compounds. Acc Chem Res. 1990;95:4601-10.

77. Donohue J. The hydrogen bond in organic crystals. J Phys Chem. 1952;56(4):502-10. doi: 10.1021/j150496a023.

78. Rodrguez-Hornedo N, Nehm SJ, Jayasankar A. Cocrystals: Design, Properties and Formation Mechanisms: Encyclopedia of Pharmaceutical Technology. $4^{\text {th }}$ ed. New York: Informa Healthcare. 2007;615-35.

79. Allen FH, Kennard O, Taylor R. Systematic analysis of structural data as a research technique in organic chemistry. Acc Chem Res. 1983;16(5):146-53.

80. Haynes DA, Chisholm JA, Jones W, Motherwell WS. Supramolecular synthon competition in organic sulfonates: A CSD survey. Cryst Eng Comm. 2004;6(95):584-8.

81. Mohammad AM, Amjad A, Sitaram PV. Hansen solubility parameter as a tool to predict cocrystal formation. Int J Pharm. 2011;407(1-2):63-71.

82. Hansen CM. Hansen solubility parameters: A user's handbook. $2^{\text {nd }}$ Ed. Boca Raton: CRC press. 2007;544.

83. Moradiya H, Islam MT, Woolam GR, Slipper IJ, Halsey S, Snowden MJ. Continuous co-crystallization for dissolution rate optimization of poorly watersoluble drug. Cryst Growth Des. 2014;14(1):189-98.

84. Sarkar A, Rohani S. Cocrystals of Acyclovir with promising physicochemical properties. J Pharm Sci. 2015;104(1):98-105.

85. Izutsu K, Koide T, Takata N, Ikeda Y, Ono M, Inoue M. Characterization and Quality control of pharmaceutical cocrystals. Chem Pharm Bull. 2016;23:2381-92.

86. Lange L, Heisel S, Sadowski G. Predicting the solubility of pharmaceutical cocrystals in solvent/anti-solvent mixtures. Molecules. 2016;21(5):593-610.

87. Lee MJ, Wang LC, Kim MJ, Kim P, Song KH, Chun NH. Controlling the polymorphism of carbamazepine-saccharine cocrystals formed during antisolvent cocrystallization using kinetic parameters. Korean J Chem Eng. 2015;32(9):1910-7.

88. Holan J, Stepanek F, Billot P, Ridvan L. The construction, prediction and measurement of co-crystal ternary phase diagrams as a tool for solvent selection. Eur J Pharm Sci. 2014;63:124-31.

89. Sarraguca MC, Ribeiro PRS, DosSantos AO, Lopes JA. Batch statistical process monitoring approach to cocrystallization process. J Pharm Sci. 2015;104(12):4099-108.

90. Sungyup J, Jonghwi L, Won K. Structures and physical properties of the cocrystals of adefovir dipivoxil with dicarboxylic acids. J Cryst Growth. 2013;373:59-63.

91. Snehal PM, Samina AJ, Poonam SK, Yogesh VP, Shashikant CD. Improvement in physicochemical properties of ezetimibe using a crystal engineering technique. Powder Technol. 2012;222:131-8.

92. Ali S, Abolghasem J. Physicochemical characterization of a new cocrystal of ketoconazole. Powder Technol. 2014;262:242-8.

93. Ning Q, Mingzhong L, Walkiria S, Nazneen M, Angela D, Gary T. Pharmaceutical cocrystals: An overview. Int J Pharm. 2011;419(1-2):1-11.

94. Anindita S, Sohrab R. Molecular salts and co-crystals of mirtazapine with promising physicochemical properties. J Pharm Biomed Analysis. 2015;110:93-9.

95. Allen FH, Motherwell WDS, Raithby PR, Shields GP, Taylor R. Systematic analysis of the probabilities of formation of bimolecular hydrogen-bonded ring motifs in organic crystal structures. New J Chem. 1999;23(1):25-34. 
96. Basavoju S, Boström D, Velaga SP. Pharmaceutical cocrystal and salts of norfloxacin. Cryst Growth Des. 2006;6(12):2699-708.

97. Yan Y, Jia-Mei C, Na G, Tong-Bu L. Improving the solubility of agomelatine via cocrystals. Cryst Growth Des. 2012;12(5):2226-33.

98. Mani G, Ung Jin J, Udhumansha U, Pushparaj H, Arthanari S, Mei MP. Chitosan cocrystals embedded alginate beads for enhancing the solubility and bioavailability of aceclofenac. Int J Biol Macromol. 2015;74:310-7.

99. Sanaa AE, Mohamed AO, Mona FA, Gamal MEM. Aerosil as a novel cocrystal co-former for improving the dissolution rate of hydrochlorothiazide. Int J Pharm. 2015;478(2):773-8.

100. Irena T, Shyam K, Jag S, RobertP, Nikoletta F. Pharmaceutical characterisation and evaluation of cocrystals: Importance of in vitro dissolution conditions and type of coformer. Int J Pharm. 2013;453(2):380-8.

101. Artem OS, Alexander PV, Alex NM, Nikolay GM, Lyudmila GK, Andrei VC, et al. Pharmaceutical cocrystals of diflunisal and diclofenac with theophylline. Mol Pharm 2014;11(10):3707-15.

102. Monika NA, Santhosh PR, Sathesh B, Subrahmanyam CVS. Solid state manipulation of lornoxicam for cocrystals - physicochemical characterization. Drug Dev Ind Pharm. 2014;40(9):1163-72.

103. Yusuke M, Toshiro F, Masatoshi K, Kentaro Y, Tatsuaki T, Tetsuya O, et al. Novel pharmaceutical cocrystal consisting of paracetamol and trimethylglycine, a new promising cocrystal former. Int J Pharm. 2014;473(12):179-86.

104. Maddileti D, Jayabun SK, Ashwini N. Soluble cocrystals of the xanthine oxidase inhibitor febuxostat. Cryst Growth Des. 2013;13(7):3188-96.

105. Adam JS, Padmini K, Lukasz W, Michael JZ, Douglas RS. Cocrystals of quercetin with improved solubility and oral bioavailability. Mol Pharm. 2011;8(5):1867-76.

106. Shete AS, Yadav AV, Murthy MS. Enhancement of dissolution rate of irbesartan by chitosan based crystal engineering technique. Ind J Pharm Edu Res. 2012;46(4):323-9.

107. Palash S, Rajesh GN, Rao Khandavilli UB, Ashwini N. Fast dissolving curcumin cocrystals. Cryst Growth Des. 2011;11(9):4135-45.

108. Palash SS, Sudalai K, Ashwini N. Pharmaceutical Cocrystals of Niclosamide. Cryst Growth Des. 2012;12(9):4588-99.

109. Rodríguez-Hornedo N, Nehm SJ, Jayasankar A. Cocrystals: Design, properties and formation mechanisms, $3^{\text {rd }}$ ed. London: Taylor and Francis. 2007.

110. Pawar JN, Amin PD. Development of efavirenz cocrystals from stoichiometric solutions by spray drying technology. Mater Today Proc. 2016;3(6):1742-51.

111. Luis P, Miguel AR, Sitaram PV, Anabela CF, Henrique AM, Edmundo GA. Screening for pharmaceutical cocrystals using the supercritical fluid enhanced atomization process. J Supercrit Fluids. 2010;53(1-3):156-64.

112. Tian Z, Xiaorui L, Qiushuo Y, Xiaoxun M. Preparation of 2:1 urea-succinic acid cocrystals by sublimation. J Cryst Growth. 2017;469:114-8.

113. Sharvil P, Vinayak U, Abhijeet M. Electrospray technology as a probe for cocrystal synthesis: Influence of solvent and coformer structure. J Drug Delivery Sci Technol. 2017;39:217-22.

114. Silvério FSF, Andreia CP, Jorge MGS, Mafalda CS, João L, DePedro FFF, et al. Synthesis of a Glibenclamide Cocrystal: Full Spectroscopic and Thermal Characterization. J Pharm Sci. 2018;107(6):1597-604.

115. Jelena D, loannis N, Svetlana I, Zorica D, Kyriakos K. Preparation of carbamazepine-Soluplus ${ }^{\circledR}$ solid dispersions by hot-melt extrusion and prediction of drug-polymer miscibility by thermodynamic model fitting. Eur $\mathrm{J}$ Pharm Biopharm. 2013;84(1):228-37.

116. Kumar S, Kishore N, Vittal, Sivakumaran MS. Process for the preparation dl-proline co-crystal of dapagliflozin. WO Patent 2017191539A1. Aurobindo Pharma Limited. 2016.

117. Tesson N, Gordo CE. Cocrystals of lorcaserin. WO Patent 2017144598 A1. 2016.

118. Kocherlakota C, Banda N. Novel co-crystal forms of agomelatine. WO Patent 2017115284 A1. Leiutis Pharmaceuticals Pvt, Ltd. 2015;1-15.

119. Albrecht W, Geier J, Sebastian, Perez D. Co-crystals of ibrutinib with carboxylic acids. WO Patent 2016156127 A1. Ratiopharm Gmbh. 2015.

120. Thakuria R, Delori A, Jones W, Lipert MP, Roy L, Rodríguez-Hornedo N. Pharmaceutical cocrystals and poorly soluble drugs. Int J Pharm. 2013;453(1):101-25.
121. Brittain HG. Pharmaceutical cocrystals: The coming wave of new drug substances. J Pharm Sci. 2013;102(2):311-7.

122. Guidance for industry: Regulatory classification of pharmaceutical cocrystals. Food and Drug Administration. 2013.

123. European Medicines Agency. Reflection paper on the use of cocrystals of active substances in medicinal products. European Medicines Agency: Science Medicines Health. 2015;1-10.

124. Yamamoto K, Tsutsumi S, Ikeda Y. Establishment of cocrystal cocktail grinding method for rational screening of pharmaceutical cocrystals. Int $\mathrm{J}$ Pharm. 2012;437(1-2):162-71.

125. Yamashita H, Hirakura Y, Yuda M, Terada K. Coformer Screening Using Thermal Analysis Based on Binary Phase Diagrams. Pharm Res. 2014;31(8):1946-57.

126. Kojima T, Tsutsumi S, Yamamoto K, Ikeda Y, Moriwaki T. High-throughput cocrystal slurry screening by use of in situ Raman microscopy and multi-well plate. Int J Pharm. 2010;399(1-2):52-9.

127. Berry DJ, Seaton CC, Clegg W, Harrington RW, Coles SJ, Horton PN, et al. Applying Hot-Stage Microscopy to Co-Crystal Screening: A Study of Nicotinamide with Seven Active Pharmaceutical Ingredients. Cryst Growth Des. 2008;8(5):1697-712.

128. Mohamed S, Tocher DA, Price SL. Computational prediction of salt and cocrystal structures-Does a proton position matter?. Int $\mathrm{J}$ Pharm. 2011;418(2):187-98.

129. Mukherjee A, Dixit K, Sarma SP, Desiraju GR. Aniline-phenol recognition: From solution through supramolecular synthons to cocrystals. IUCrJ. 2014;1(4):228-39.

130. Tomaszewska I, Karki S, Shur J, Price R, Fotaki N. Pharmaceutical characterisation and evaluation of cocrystals: Importance of in vitro dissolution conditions and type of conformer. Int J Pharm. 2013;453(2):380-8.

131. Reutzel-Edens SM, Wouters J, Quere L. Pharmaceutical Salts and Cocrystals. Cambridge: Royal Society of Chemistry. 2011;212-46.

132. Li P, Chu Y, Wang L, Wenslow RM, Yu K, Zhang $\mathrm{H}$, et al. Structure determination of the theophylline-nicotinamide cocrystal: a combined powder XRD, 1D solid-state NMR and theoretical calculation study. Cryst Eng Comm. 2014;16(5):3141-7.

133. Trask AV, Motherwell WD, Jones W. Solvent-drop grinding: Green polymorph control of cocrystallisation. Chem Commun. 2004;7(7):890-1.

134. Limwikrant W, Nagai A, Hagiwara Y, Higashi K, Yamamoto K, Moribe K. Formation mechanism of a new carbamazepine/malonic acid cocrystal polymorph. Int J Pharm. 2012;431(1-2):237-40.

135. Braun DE, Tocher DA, Price SL, Griesser UJ. The Complexity of Hydration of Phloroglucinol: A Comprehensive Structural and Thermodynamic Characterization. J Phys Chem B. 2012;116(13):3961-72.

136. Childs SL, Stahly GP, Park A. The Salt-Cocrystal Continuum: The Influence of Crystal Structure on Ionization State. Mol Pharm. 2007;4(3):323-38.

137. Cowan JA, Howard JAK, Mason SA, Mclntyre GJ, Lo SMF, Mak T, et al. Neutron diffraction studies of the 1: 1 and 2: 1 cocrystals of benzene-1, 2, 4, 5-tetracarboxylic acid and 4, 4'-bipyridine. Acta Crystallogr. 2006;62(Pt 4):0157-61.

138. Ando S, Kikuchi J, Fujimura $\mathrm{Y}$, Ida $\mathrm{Y}$, Higashi $\mathrm{K}$, Moribe $\mathrm{K}$, et al. Physicochemical Characterization and Structural Evaluation of a Specific 2:1 Cocrystal of Naproxen-Nicotinamide. J Pharm Sci. 2012;101(9):3214-21.

139. Stevens JS, Byard SJ, Muryn CA, Schroeder SL. Identification of Protonation State by XPS, Solid-State NMR and DFT: Characterization of the Nature of a New Theophylline Complex by Experimental and Computational Methods. J Phys Chem B. 2010;114(44):13961-9.

140. Yong D, Huili Z, Jiadan X, Hong XF, Qi Z, Yi X, Yafang L, et al. Raman and terahertz spectroscopical investigation of cocrystal formation process of piracetam and 3-hydroxybenzoic acid. Spectrochim Acta A. 2015;139(15):488-94.

141. Yong Du, Hong XF, Qi Zhang, Hui LZ, Zhi H. Spectroscopic investigation on cocrystal formation between adenine and fumaric acid based on infrared and Raman techniques. Spectrochim Acta A. 2016;153:580-5.

142. Yong D, Jiadan X, Qiang C, Qi Zhang. Spectroscopic investigation on structure and $\mathrm{pH}$ dependent Cocrystal formation between gamma-aminobutyric acid and benzoic acid. Spectrochim Acta A. 2018;191:377-81.

143. Yaguo W, Jiadan X, Qiqi W, Shunji J, Ziming Z, Zhi H, et al. Structural investigation of a 2:1 co-crystal between diflunisal and isonicotinamide based 
on terahertz and Raman spectroscopy. Spectrochim Acta A. 2019;216:98104.

144. Manin AN, Voronin AP, Drozd KV, Manin NG, Bauer BA, Perlovich GL. Cocrystal screening of hydroxybenzamides with benzoic acid derivatives: $A$ comparative study of thermal and solution-based methods. Eur J Pharm Sci. 2014;65:56-64.

145. Rahman Z, Agarabi C, Zidan AS, Khan SR, Khan MA. Physico-mechanical and Stability Evaluation of Carbamazepine Cocrystal with Nicotinamide. AAPS Pharm Sci Tech. 2011;12(2)693-704.

146. Padrela L, DeAzevedo EG, Velaga SP. Powder X-ray diffraction method for the quantification of cocrystals in the crystallization mixture Drug Dev. Ind Pharm. 2012;38(8):923-9.

147. Hasa D, Schneider RG, Voinovich D, Jones W. Cocrystal Formation through Mechanochemistry: from Neat and Liquid-Assisted Grinding to PolymerAssisted Grinding. Angew Chem Int Ed Engl. 2015; 54(25):7371-5.

148. Keramatnia F, Shayanfar A, Jouyban A. Thermodynamic Solubility Profile of Carbamazepine-Cinnamic Acid Cocrystal at Different pH. J Pharm Sci. 2015;104(8):2559-65.

149. Lee HG, Zhang GG, Flanagan DR. Cocrystal Intrinsic Dissolution Behavior Using a Rotating Disk. J Pharm Sci. 2011;100(5):1736-44.

150. Grossjohann C, Eccles KS, Maguire AR, Lawrence SE, Tajber L, Corrigan $\mathrm{OI}$, et al. Characterisation, solubility and intrinsic dissolution behaviour of benzamide: Dibenzyl sulfoxide cocrystal. Int J Pharm. 2012;422(1-2):24-32.

151. DeSmet L, Saerens L, DeBeer T, Carleer R, Adriaensens P, Bocxlaer JV, et al. Formulation of itraconazole nanococrystals and evaluation of their bioavailability in dogs. Eur J Pharm Biopharm. 2014;87(1):107-13.

152. Hisada H, Inoue M, Koide T, Carriere J, Heyler R, Fukami T. Direct HighResolution Imaging of Crystalline Components in Pharmaceutical Dosage Forms Using Low-Frequency Raman Spectroscopy. Org Process Res Dev. 2015;19(11):1796-8.

153. Remenar JF, Peterson ML, Stephens PW, Zhang Z, Zimenkov Y, Hickey MB. Celecoxib: Nicotinamide dissociation: Using excipients to capture the cocrystal's potential. Mol Pharm. 2007;4(3):386-400.

154. Alhalaweh A, Ali HRH, Velaga SP. Effects of polymer and surfactant on the dissolution and transformation profiles of cocrystals in aqueous media. Cryst Growth Des. 2014;14(2):643-8.

155. Guo M, Wang K, Hamill N, Lorimer K, Li M. Investigating the influence of polymers on supersaturated flufenamic acid cocrystal solutions. Mol Pharm. 2016;13(9):3292-307.

156. Wang C, Tong Q, Hou X, Hu S, Fang J, Sun CC. Enhancing bioavailability of dihydromyricetin through inhibiting precipitation of soluble cocrystals by a crystallization inhibitor. Cryst Growth Des. 2016;16(9):5030-9.

157. Li M, Qiu S, Lu Y, Wang K, Lai X, Rehan M. Investigation of the effect of hydroxypropyl methylcellulose on the phase transformation and release profiles of carbamazepine-nicotinamide cocrystal. Pharm Res. 2014;31(9):2312-25.

158. Ullah M, Hussain I, Sun CC. The development of carbamazepinesuccinic acid cocrystal tablet formulations with improved in vitro and in vivo performance. Drug Dev Ind Pharm. 2015;42(6):969-76.

159. Huang $\mathrm{N}$, Rodríguez-Hornedo $\mathrm{N}$. Effect of micellar solubilization on cocrystal solubility and stability. Cryst Growth Des. 2010;10(5):20503.

160. Lipert MP, Roy L, Childs SL, Rodriguez-Hornedo N. Cocrystal solubilization in biorelevant media and its prediction from drug solubilization. J Pharm Sci. 2015;104(12):4153-63.

161. Kuminek G, Cao F, DaRocha ABDO, Cardoso SG, Rodríguez-Hornedo N. Co-crystals to facilitate delivery of poorly soluble compounds beyond-rule-of-5. Adv Drug Del Rev. 2016;101:143-66.

162. Bethune SJ, Huang $\mathrm{N}$, Jayasankar A, Rodríguez-Hornedo $\mathrm{N}$. Understanding and predicting the effect of cocrystal components and pH on cocrystal solubility. Cryst Growth Des. 2009;9(9):3976-88.

163. Cheney ML, Shan N, Healey ER, Hanna M, Wojtas L, Zaworotko MJ. Effects of crystal form on solubility and pharmacokinetics: A crystal engineering case study of lamotrigine. Cryst Growth Des. 2009;10(1):394-405.

164. Ghosh S, Mondal A, Kiran M, Ramamurty U, Reddy CM. The role of weak interactions in the phase transition and distinct mechanical behavior of two structurally similar caffeine co-crystal polymorphs studied by nano- indentation. Cryst Growth Des. 2013;13(10):443541.

165. Picker KM. "Soft tableting": A new concept to tablet pressure sensitive ma- terials. Pharm Dev Technol. 2004;9(1):107-21.

166. Schmidt AG, Wartewig S, Picker KM. Potential of carrageenans to protect drugs from polymorphic transformation. Eur J Pharm Biopharm. 2003;56(1):10110.

167. Eddleston MD, Thakuria R, Aldous BJ, Jones W. An investigation of the causes of cocrystal dissociation at high humidity. J Pharm Sci. 2014;103(9):2859-64.

168. Karki S, Friščić T, Jones W, Motherwell WDS. Screening for pharmaceutical cocrystal hydrates via neat and liquid-assisted grinding. Mol Pharm. 2007;4(3):347-54.

169. Sovago I, Wang W, Qiu D, Raijada D, Rantanen J, Grohganz H, et al. Properties of the sodium naproxen-lactose- tetrahydrate cocrystal upon processing and storage. Molecules. 2016;21(4):509.

170. Zhang GGZ, Law D, Schmitt EA, Qiu Y. Phase transformation considerations during process development and manufacture of solid oral dosage forms. Adv Drug Del Rev. 2004;56(3):371-90.

171. Zhou Z, Li W, Sun WJ, Lu T, Tong HHY, Sun CC. Resveratrol cocrystals with enhanced solubility and tabletability. Int J Pharm. 2016;509(1-2):391-9.

172. Connolly SJ, Eikelboom J, Joyner C. Apixaban in patients with atrial fibrillation. N Eng J Med. 2011;364(9):806-17.

173. Granger CB, Alexander JH, McMurray JJV. Apixaban versus warfarin in patients with atrial fibrillation. N Eng J Med. 2011;365(11):981-92.

174. Chen Y, Li L, Yao J, Ma Y, Chen JM, Lu TB. Improving the Solubility and Bioavailability of Apixaban via Apixaban-Oxalic Acid Cocrystal. Cryst Growth Des. 2016;16(5):2923-30.

175. Frost C, Nepal S, Wang J. Safety, pharmacokinetics and pharmacodynamics of multiple oral doses of apixaban, a factor Xa inhibitor, in healthy subjects. $\mathrm{Br}$ J Clin Pharmacol. 2013;76(5):776-86.

176. Yuan LC, Dahl TC, Oliyai R. Effect of carbonate salts on the kinetics of acidcatalyzed dimerization of adefovir dipivoxil. Pharm Res. 2000;17(9):1098103.

177. Dong Y, Zhang Y, Xiang B, Deng H, Wu J. Modeling of autocatalytic hydrolysis of adefovir dipivoxil in solid formulations. Yakugaku Zasshi. 2011;131(4):64354.

178. Benzaria S, Pélicano H, Johnson R. Synthesis, in vitro antiviral evaluation and stability studies of bis(S-acyl-2-thioethyl) ester derivatives of 9-[2-(phosphonomethoxy) ethyl] adenine (PMEA) as potential PMEA prodrugs with improved oral bioavailability. J Med Chem. 1996;39(25):4958-65.

179. Arimilli MN, Kelly DE, Lee TTK. Nucleotide analog compositions. US 6451340. 2002;B1.

180. Prohens R, Barbas R, Portell A, Font-Bardia M, Alcobé X, Puigjaner C. Expanding the Crystal Form Landscape of the Antiviral Drug Adefovir Dipivoxil. Cryst Growth Des. 2014;15(1):475-84.

181. Jung S, Lee J, Kim IW. Structures and physical properties of the cocrystals of adefovir dipivoxil with dicarboxylic acids. J Cryst Growth. 2013;373:59-63.

182. Gao Y, Gao J, Liu Z. Coformer selection based on degradation pathway of drugs: A case study of adefovir dipivoxil-saccharin and adefovir dipivoxilnicotinamide cocrystals. Int J Pharm. 2012;438(1):327-35.

183. Anderson BJ. Paracetamol (Acetaminophen): Mechanisms of action. Paediatr Anaesth. 2008;18(10):915-21.

184. Ottani A, Leone S, Sandrini M, Ferrari A, Bertolini A. The analgesic activity of paracetamol is prevented by the blockade of cannabinoid CB 1 receptors. Eur J Pharm. 2006;531(1):280-1.

185. DiMartino P, Guyot-Hermann AM, Conflant P, Drache M, Guyot JC. A new pure paracetamol for direct compression: the orthorhombic form. Int J Pharm. 1996;128(1):1-8.

186. Karki S, Friščić T, Fábián L, Laity PR, Day GM, Jones W. Improving mechanical properties of crystalline solids by cocrystal formation: New compressible forms of paracetamol. Adv Mat. 2009;21(38-39):3905-9.

187. Maeno Y, Fukami T, Kawahata M, Yamaguchi K, Tagami T, Ozeki T, et al. Novel pharmaceutical cocrystal consisting of paracetamol and trimethylglycine, a new promising cocrystal former. Int J Pharm. 2014;473(1):179-86.

188. Elbagerma MA, Edwards HGM, Munshi T, Scowen IJ. Identification of a new cocrystal of citric acid and paracetamol of pharmaceutical relevance. Cryst Eng Comm. 2011;13(6):1877-84. 
189. Srirambhatla VK, KraftA, Watt S, Powell AV. Crystal design approaches for the synthesis of paracetamol co-crystals. Cryst Growth Des. 2012;12(10):4870-9.

190. Hirasawa N, Okamoto H, Danjo K. Lactose as a low molecular weight carrier of solid dispersions for carbamazepine and ethenzamide. Chem Pharm Bull. 1999;47(3):417-20.

191. Matsumoto K, Nakai Y, Yonemachi E, Oguchi T, Yamamoto K. Effect of pore size on the gaseous adsorption of ethenzamide on porous crystalline cellulose and the physicochemical stability of ethenzamide after storage. Chem Pharm Bull. 1998;46(2):314-8.

192. Back KR, Davey RJ, Grecu T, Hunter CA, Taylor LS. Molecular conformation and crystallization: The case of ethenzamide. Cryst Growth Des. 2012;12(12):6110-7.

193. Aitipamula S, Chow PS, Tan RB. Trimorphs of a pharmaceutical cocrystal involving two active pharmaceutical ingredients: potential relevance to combination drugs. Cryst Eng Comm. 2009;11(9):1823-27.

194. Aitipamula S, Chow PS, Tan RB. Polymorphs and solvates of a cocrystal involving an analgesic drug, ethenzamide and 3, 5dinitrobenzoic acid. Cryst Growth Des. 2010;10(5):2229-38.

195. Andreeff M, Stone R, Michaeli J, Young CW, Tong WP, Sogoloff H, et al. Hexamethylene bisacetamide in myelodysplastic syndrome and acute myelogenous leukemia: A phase II clinical trial with a differentiation-inducing agent. Blood. 1992;80(10):2604-9.

196. Siegel DS, Zhang X, Feinman R, Teitz T, Zelenetz A, Richon VM, et al. Hexamethylene bisacetamide induces programmed cell death (apoptosis) and down-regulates BCL-2 expression in human myeloma cells. Proc Natl Acad Sci U.S.A. 1998;95(1):162-6.

197. Aakeröy CB, Forbes S, Desper J. Using cocrystals to systematically modulate aqueous solubility and melting behavior of an anticancer drug. J Am Chem Soc. 2009;131(47):17048-9.

198. Dessen A, Quemard A, Banchard JS, Sacchettini JC. Crystal structure and function of the isoniazid target of Mycobacterium tuberculosis. Sci. 1995;267(5204):1638.

199. Singh S, Mariappan TT, Sharda N, Singh B. Degradation of rifampicin, isoniazid and pyrazinamide from prepared mixtures and marketed single and combination products under acid conditions. Pharm Pharmacol Com. 2000;6(11):491-4.

200. Aitipamula S, Wong ABH, Cho PS, Tan RBH. Novel solid forms of the antituberculosis drug, Isoniazid: Ternary and polymorphic cocrystals. Cryst Eng Comm. 2013;15(29):5877-87.
201. Swapna B, Maddileti D, Nangia A. Cocrystals of the tuberculosis drug isoniazid: Polymorphism, isostructurality and stability. Cryst Growth Des. 2014;14(11):5991-6005.

202. Sarcevica I, Orola L, Veidis MV, Podjava A, Belyakov S. Crystal and molecular structure and stability of isoniazid cocrystals with selected carboxylic acids. Cryst Growth Des. 2013;13(3):1082-90.

203. Putra OD, Furuishi T, Yonemochi E, Terada K, Uekusa H. Drug-drug multicomponent crystals as an effective technique to overcome weaknesses in parent drugs. Cryst Growth Des. 2016;16(7):3577-81.

204. Haneef J, Chadha R. Drug-Drug Multicomponent Solid Forms: Cocrystal, Coamorphous and Eutectic of Three Poorly Soluble Antihypertensive Drugs Using Mechanochemical Approach. AAPS Pharm Sci Tech. 2017;18(6):1-12.

205. Almansa C, Merce R, Tesson N, Farran J, Tomàs J, Plata-Salamán CR. Co-crystal of Tramadol Hydrochloride-Celecoxib (ctc): A Novel API-API Cocrystal for the Treatment of Pain. Cryst Growth Des. 2017;17(4):1884-92.

206. Videla S, Lahjou M, Vaque A, Sust M, Encabo M, Soler L, et al. Singledose pharmacokinetics of cocrystal of tramadol-celecoxib: Results of a fourway randomized openlabel phase I clinical trial in healthy subjects. $\mathrm{Br} \mathrm{J}$ Clin Pharmacol. 2017;83(12):2718-28.

207. Vladimir P. British Drug Houses Ltd. Compound of betaine and chloral and method for preparing same. US Patent No. 3028420.

208. O' Nolan D, Perry ML, Zaworotko MJ. Chloral hydrate polymorphs and cocrystal revisited: solving two pharmaceutical cold cases. Crystal Growth Design. 2016;16(4):2211-7.

209. Loiseau PJM. Clinical experience with new antiepileptic drugs: Antiepileptic drugs in Europe. Epilepsia. 1999;40(S6):3-8.

210. Alsenz J, Kansy M. High throughput solubility measurement in drug discovery and development. Adv Drug Deliv. 2007;59(7):546-67.

211. Bauer JF, Shada DM. Acid salts of valproic acid. US Patent. 4558070.

212. Peikova L, Manova M, Georgieva S, Petrova G. Enantiomers novelty protection and its influence on generic market: An example with escitalopram patent protection. Biotechnol Biotechnolog Equip. 2013;27(4):4044-7.

213. Harrison WTA, Yathirajan HS, Bindya S, Anilkumarb HG, Devaraju. Escitalopram oxalate: co-existence of oxalate dianions and oxalic acid molecules in the same crystal. Acta Crystallogr C. 2007;C63:0129-31.

214. Cipriani A, Furukawa TA, Salanti G, Chaimani A, Lauren ZA, Yusuke O, et al. Comparative efficacy and acceptability of 21 antidepressant drugs for the acute treatment of adults with major depressive disorder: A systematic review and network meta-analysis. Lancet. 2018;391(10128):1357-66.

\section{PICTORIAL ABSTRACT}

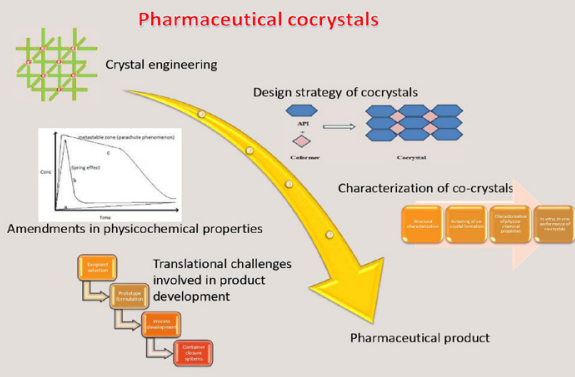

\section{About Authors}

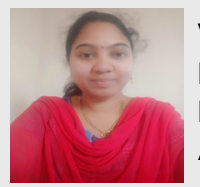

Venkata Deepthi Vemuri: Assistant Professor, Maharajah's College of Pharmacy, Phool Baugh, Vizianagaram-535002, Andhra Pradesh, INDIA.

Dr. Srinivas Lankalapalli: GITAM Institute of Pharmacy, GITAM (Deemed to be University), Visakhapatnam, Andhra Pradesh, INDIA.

Cite this article: Vemuri VD, Lankalapalli S. Insight into Concept and Progress on Pharmaceutical Co-Crystals: An Overview. Indian J of Pharmaceutical Education and Research. 2019;53(4s):s522-s538. 